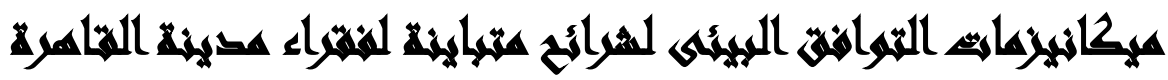

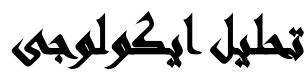

[v]

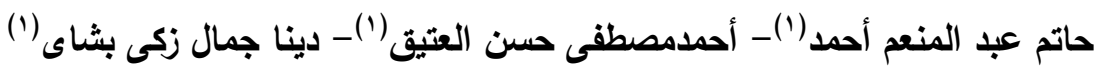

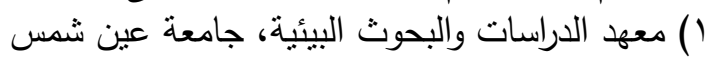

\section{المستخلم}

هدف البحث إلى التعرف على ميكانيزمات التوافق البيئى لشرائح منباينة لفقراء مدينة

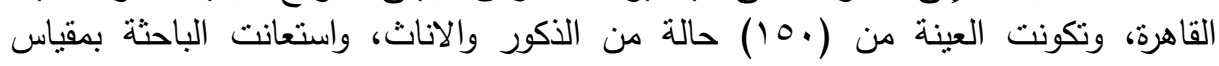

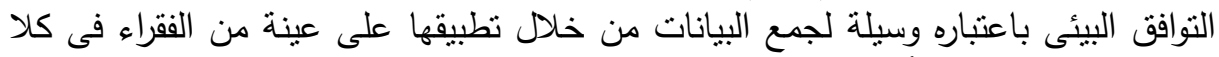

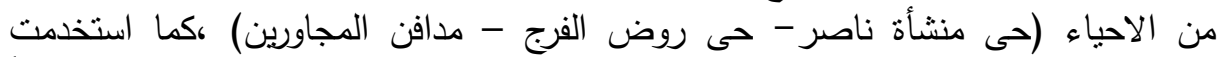

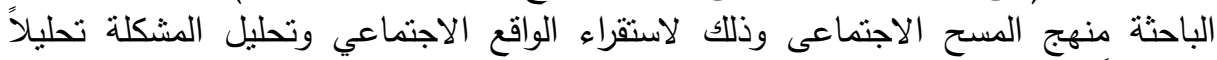

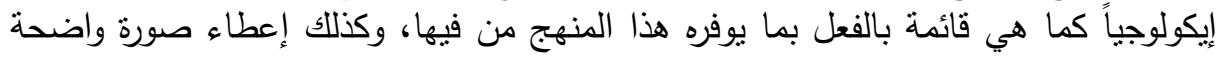

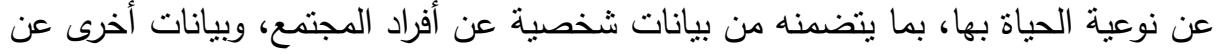
البيئة المحيطة، واستعانت الباحثة بنظرية(التحليل النفسي لفرويد - المدرسة السلوكية-الئهية المدرسة

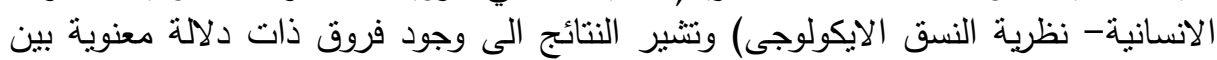

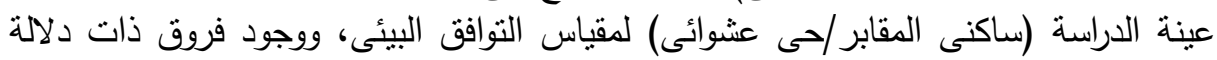

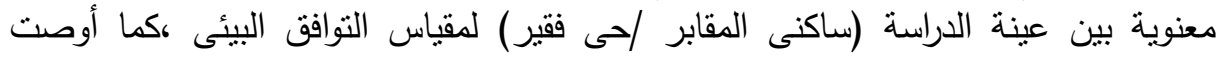

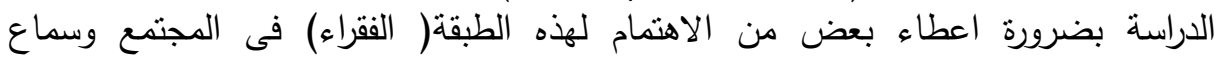

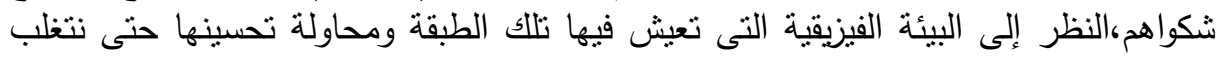

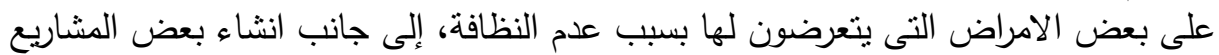

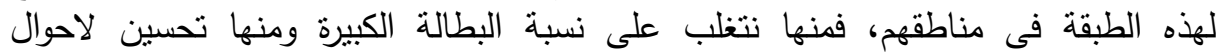

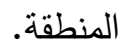

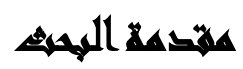

منذ البدايات الأولى للألفية الثالثة حظيت قضية الفقر باهنمام الدول العربية، فلم تعد القضية تقتصر على مجرد الافتقار إلى الدخل وعدم كفايته لتأمين الحد الأدنى للمعيشة 
المقبول اجتماعياً لملايين البشر، إنما تجاوزتها لنتمل فقر القدرة الذي ينصرف إلى تدني مستوى قدرات الإنسان إلى الحد الذي يمنعه من المشاركة في عملية التتمية وجني ثمارها. وفي ظل الزيادة السكانية الكبيرة مع ضعف ومحدودية الموارد الاقتصادية المتاحة

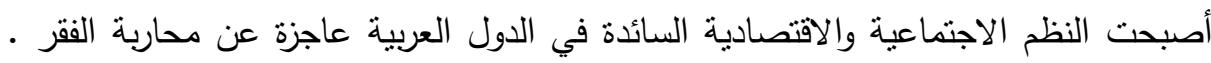

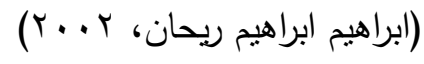

وقد استرعى موضوع الفقر لكونه يمثل مشكلة بالغة الخطورة في نظر المجتمع الدولي

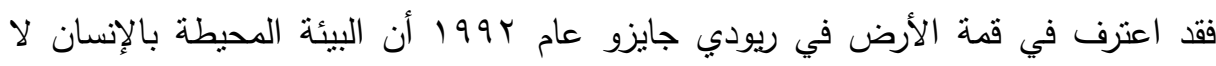

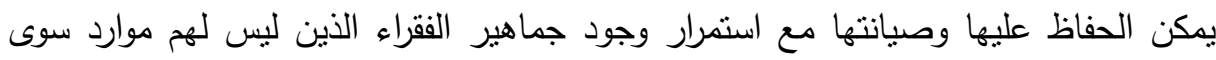
جمع المنح الضئيلة للطبيعة المحيطة لهم، وفي مؤتمر الأمم المتحدة عن السكان والتتمية

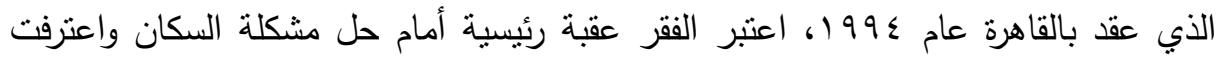
القمة التي تتاولت التتمية الاجتماعية عام 1990 أيضاً أن الفقر مع كونه الممثل في الحرمان المان

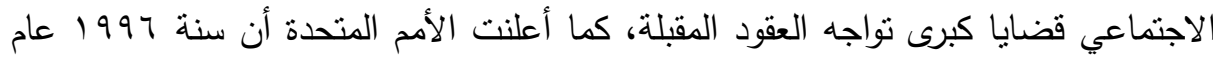

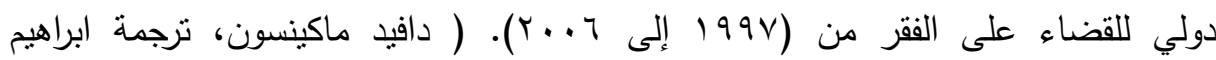
عباس، (1997)

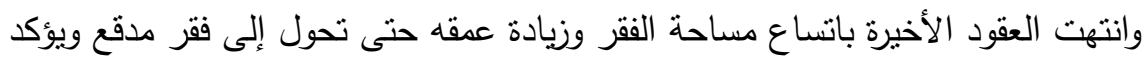
هذه الحقيقة الاهتمام العالمي الذي زادت مساحته منذ أواخر الثمانينيات ولا يزال هذا الاهنمام

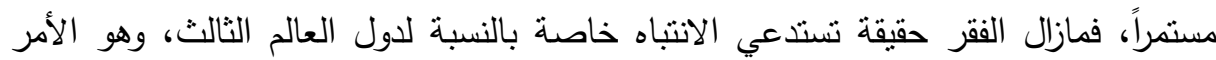

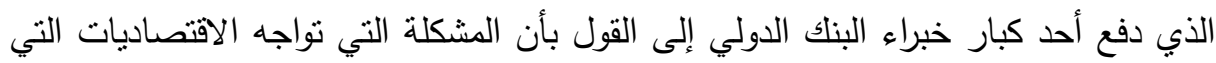

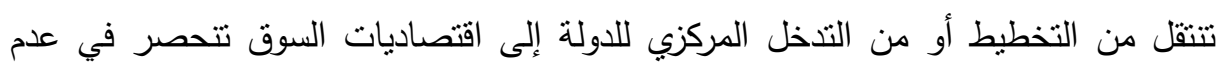

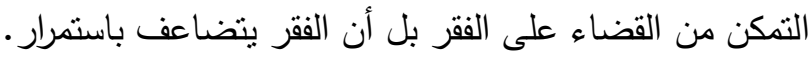

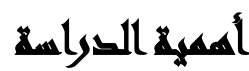

1-إن ما نشاهده من مآسي في الحياة اليومية الآن دفعنا إلى تقصي الأسباب الفعلية لظاهرة الفقر ومشكلاته المختلفة. 
r-تمنل هذه الدراسة استجابة للواقع الاجتماعي المتردي الذي تعيشه فئات واسعة ومازالت هذه الفئات تخضع لثنى أساليب المحاصرة والتهميش. r- نرجع أهمية مشكلة الفقر إلى أنها نؤرق الغالبية العظمى من دول العالم العرب العرب وبالأخص مصر - (ع- تقدم عرض شامل لمختلف مفاهيم الفقر وأساليبه وطرق قياسه.

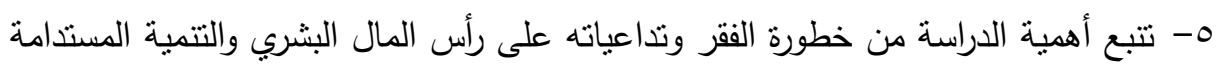
والسلام الاجتماعي.

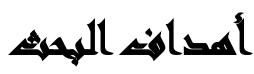

1. التعرف على ميكانيزمات التوافق الاجتماعي والنفسي والبيئى للفقراء. r. ت بتاول مشكلة الفقر نظرياً. r. محاولة التعمق في حياة هؤلاء الفقراء من خلال دراسة الحالة. ع. تحليل الواقع الفعلي تحليلاً إيكولوجياً لظاهرة الفقر كظاهرة ذاء هات أبعاد اقتصادية واجتماعية.

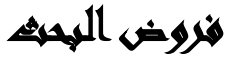

1-توجد فروق إحصائية ذات دلالة معنوية فى التوافق البيئى بين افراد عينة الدراسة (ساكني المقابر/حي عشوائي) بعد تطبيق مقياس التوافق البيئي. r-توجد فروق إحصائية ذات دلالة معنوية فى التوافق البيئى بين افراد عينة الدراسة (ساكني المقابر/حي فقير) بعد تطبيق مقياس التوافق البيئي. r-توجد فروق إحصائية ذات دلالة معنوية فى التوافق البيئى بين افراد عينة الدراسة (حي لئي عشوائي/حي فقير ) بعد نطبيق مقياس التوافق البيئي. ع-توجد فروق احصائية ذات دلالة معنوية فى التوافق البيئى بين افراد عينة الدراسة تبعا لبعائ لمتغير النوع بعد تطبيق مقياس التوافق البيئى . 


\section{مهزاهبه التراسة}

ميكانيزمات Mecanismes: كلمة فرنسية أصلها لاتيني Mecanismes وتعني ترتيب

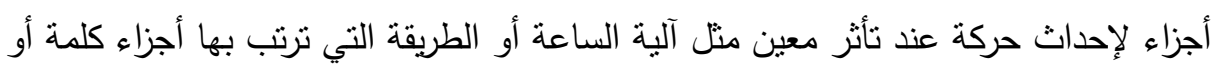

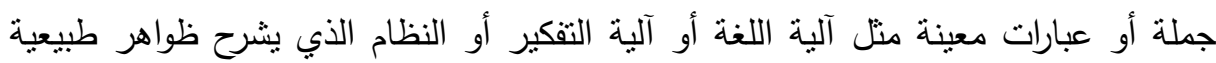
عن طريق الحركة مثل آلية ديكارت: ) Dictionnaire Hachette, Paris 2009, p. .(1016

مفهوم التوافق فى علم النفس: يذكر "صبرى جرجس" بأنه يمكن النظر إلى التوافق

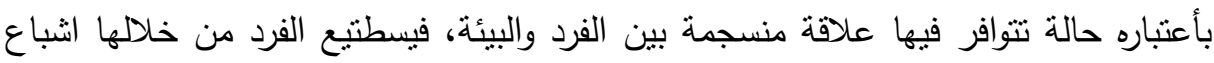
معظم حاجاته مع قبول ما تفرضه عليه البيئة من مطالب، فالتوافق هو العطلية التى تتطوى لته

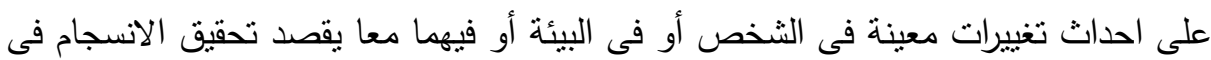

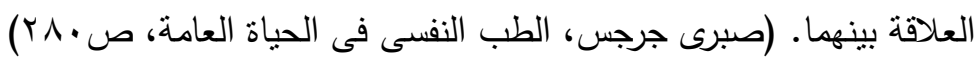
يعرف النوافق بأنه علاقة اتساق مع البيئة، وتتضمن قدرة الفرد على إثباع معظم

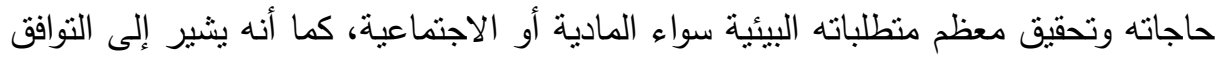

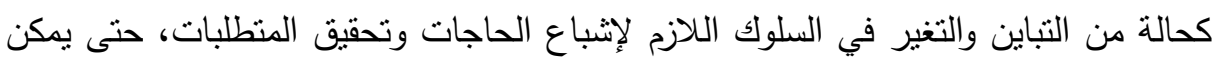

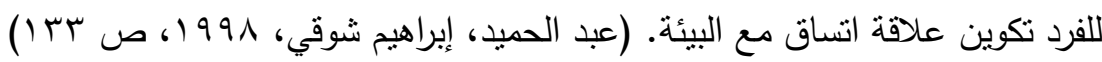
التوافق البيئي: إن التوافق البيئي بتضمن وجود نوازن ثابت بين الكائن الحي والبيئة وتكوين علاقة انسجامية مع البيئة يكون فيها الفرد قادر على إثباع معظم منطلباته وحاجاته ويستطيع مواجهة منطلبات النمو الجسمية والاجتماعية ويقوم بإحداث التغيرات المطلوبة في نفس الفرد

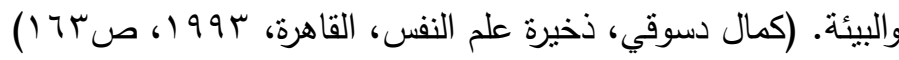
ونجد أن التوافق مع البيئة يكون إما تغير في البيئة نفسها أو تعديلات في علاقة الفرد

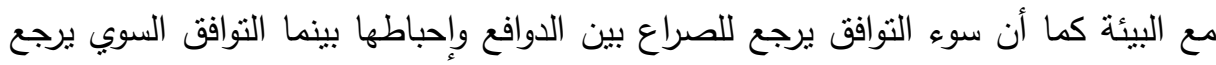
إلى العلاقة المستعملة بين الفرد والبيئة لإثتباع الحاجات للفرد وعدم التوافق يرجع لعدم القدرة على مقابلة مطالب البيئة وبذلك ترى أن التوافق يشمل العلاقة الحسنة بين الفرد والبيئة والتي 
تحتوي على تغيرات وتعديلات للأفضل. (عباس محمود عوض، الموجه في الصحة النفسية،

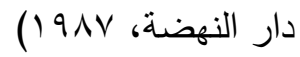

مفهوم الفقر: يعرف قاموس علم الاجتماع الفقر بأنه " مستوى معيشى منخفض لا يفى

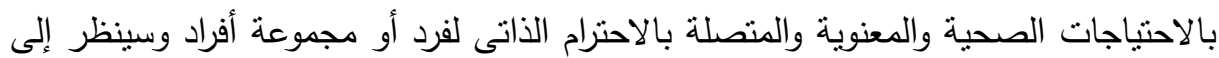

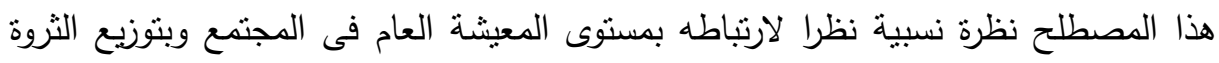

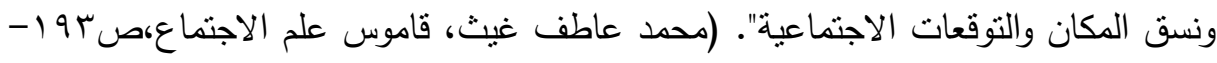

المفاهيم التى تناولتها المؤسسات الاولية: تعريف مكتب العمل الدولى التابع لهيئة

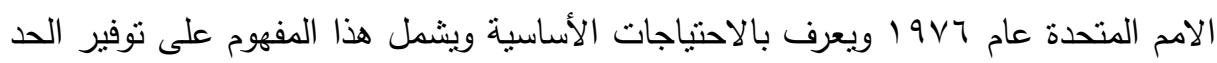
الأدنى مما يلزم الأسرة للاستهلاك الثخصى من الغذاء والملبس والمسكن مع تمكين الأسرة

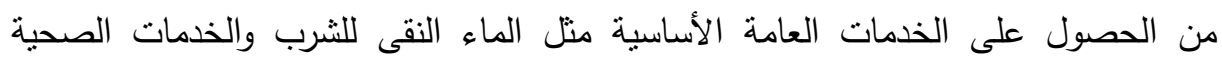
والتعليم والمواصلات وتوفير فرص عمل لأفراد الأسرة (محد الغنيمى، محاضرات فى الثى

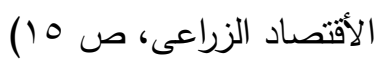
الفقر هو الحرمان من الخيارات والفرص، وهو انتهاك الكرامة الإنسانية، فهي تعني نقصًا في القدرة الأساسية على المشاركة الفعالة في المجتمع، كما يعني عدم وجود ما يكفي لإطعام أسرة وكسوتها وعدم وجود مدرسة وعدم وجود وظيفة لكسب المعيشة منها، وهو ما يعني انعدام

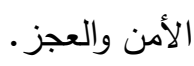
فقد حاول البنك الدولي وضع تعريف شامل للفقر مفاده أنه عدم القدرة على تحقيق الحد

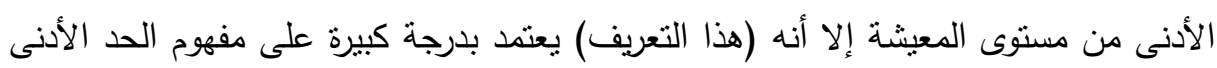

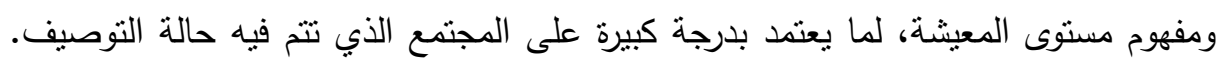

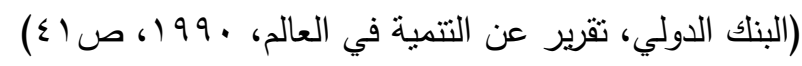




\section{القراسايت الساريه}

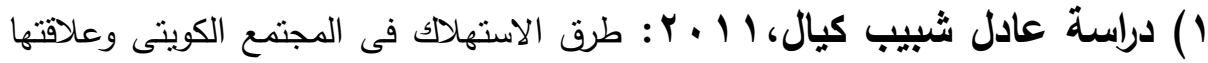

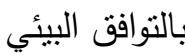

هدفت الدراسة الى: التعرف على دور المتغيرات الاجتماعية والاقتصادية "مثل الدخل والتعليم والمهنة والبيئة " وأثرها فى تحقيق التوافق الاجتماعى لدى الاسر فى المجتمع الكويتى، ومعرفة نمط الاستهلاك لكلا من الغذاء والمسكن والملبس والعلاج والترفيه، وعلاقة ذلك بالتوافق الاجتماعى لدى الاسر، وتحديد الثقافة الحالية للاستهلاك والتى تتمنل فى كم الممتلكات

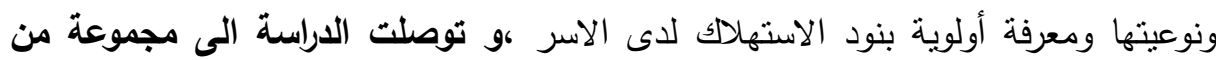

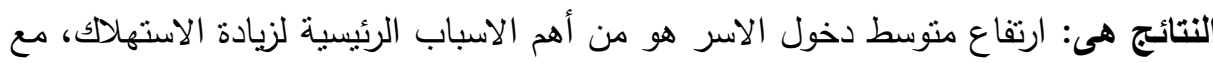

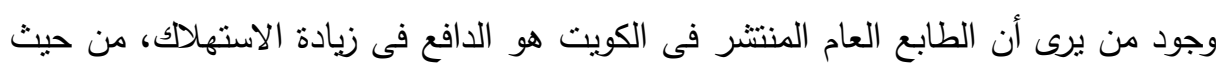
المظهر والبحث الزائد عن الطرف، ويوجد أثر متبادل بين ارتفاع متوسط دخل الاسرة وزيادة الاستهلاك والعلاقة بينهم طردية.

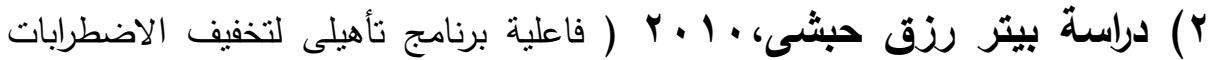
السلوكية لدى الاطفال الذاتويون وتتمية اليات التوافق البيئى لايهم).

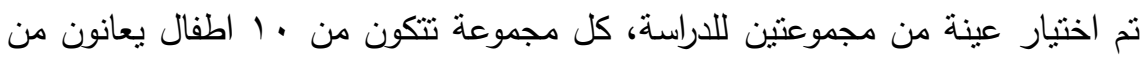

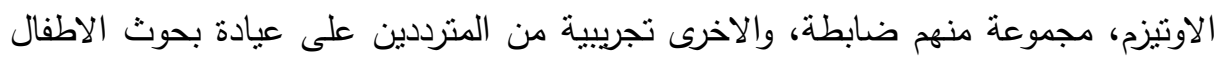

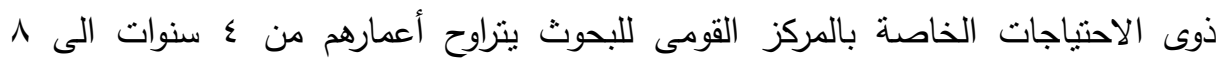
سنوات، خاليين من الامراض الجسمية وفى ظروف أسرية طبيعية، ويمثلون مستويات

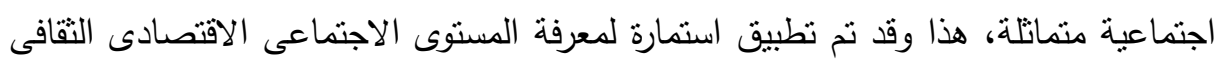
للوالدين، وايضا مقياس تقدير الاوتيزم (cars) لتحديد مستوى الاوتيزم، وايضا مقياس الاضطراب السلوكى للاطفال الذاتويون.

ومن نتائج البحث: اعادة تتظيم بيئة أطفال المجموعة التجريبية وتزويدها بكثير من الادوات

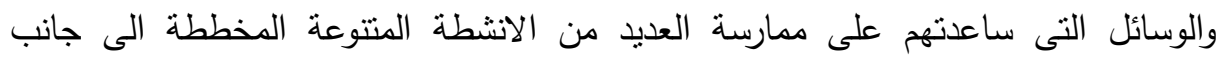
التقاعل مع هذه البيئة، كما أن مما لا شك فيه أن التدريب العملى على المهارات العلى الحياتية 164

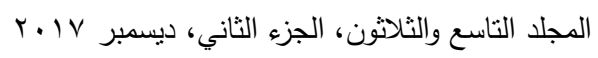


والمهارات العملية والحرفية البسيطة بساعد الاطفال الذاتويون فى الاعتماد على أنفسه بقدر

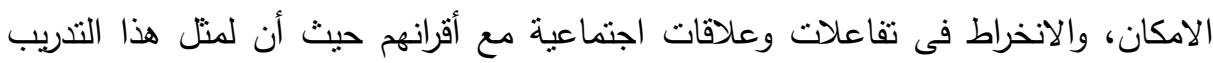
أثنار على الجوانب النفسية و الاجتماعية والانفعالية لديهر مما يكسبهم تقبل الاخرين وتقديرهم.

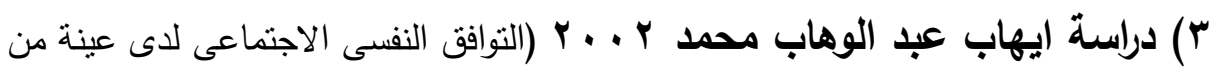
الاطفال المهجرين بسبب انهيار منازلهم واثز ذلك غلى اتجاهاتهم البيئية). تهدف الدراسة إلى التعرف على التوافق النفسى والاجتماعى لدى الاطفال المهجرين اضطرارا بسبب انهيار منازلهم، وايضا التعرف على الاتجاهات البيئية للاطفال المهرين لإلى الطرارا

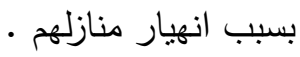
أجريت الدراسة على عينة قوامها . . . طفل مقسمة إلى مجموعنين: المجموعة الاولى مكونة

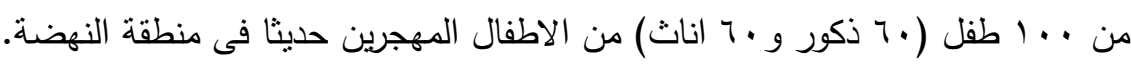

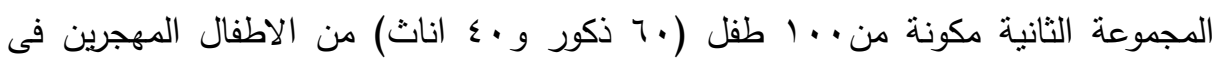

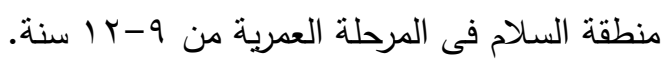
اعتمد الباحث فى دراسته على مجموعة من الادوات: مقياس التوافق النفسى، مقياس التوافق

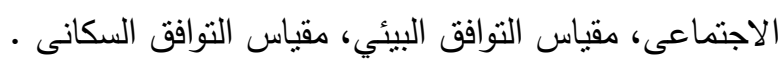
وقد توصلت الاراسة إلى التالي: توجد فروق دالة احصائيا فى مستوى التوافق النفسى لصنئي لصالح

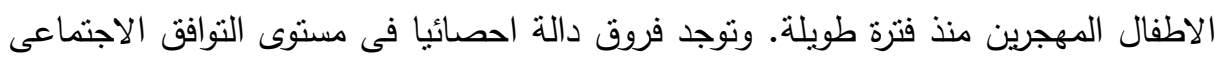
والسكنى والاتجاهات البيئية لصالح الاطفال المهجرين منذ فترة طويلة.

\section{الإطار المنظرى للقوراسة}

يتميز الإنسان عن بقية الكائنات الحية بالصفة الاجتماعية، ولا يمكنتا بأي حال من

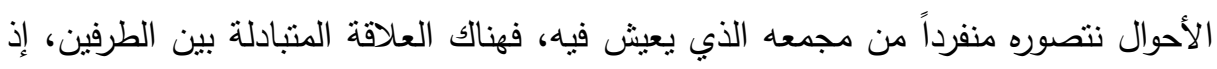

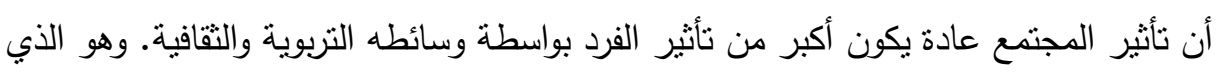
يصنع الثخصية مما يجعل من الصعوبة خروج الثخص عن القواعد الاجتماعية المتفق عليها. ونجد أن البيئة الطبيعية ترتبط بشكل خاص بالتكيف البيولوجي البولة أما البيئة الاجتماعية

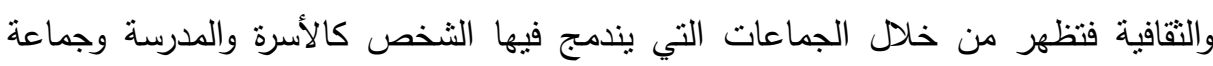

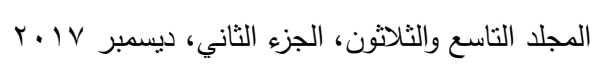


الرفاق والمؤسسات الإعلامية وكلها تؤثر بشكل أو بآخر فى نوافق الفرد.(محد حسين، (r T r...

مستويات التوافق: ينمو الإنسان من خلال تفاعل مجموعة من الدحددات الوراثية والبيئية

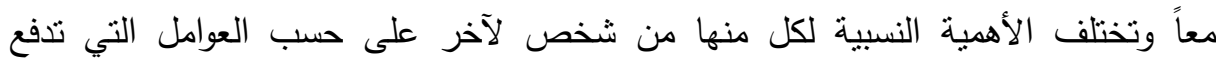

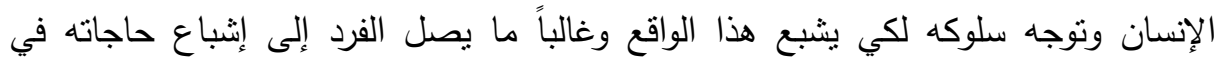
مواقف الحياة المألوفة إلإ أنه لا مفر من وجود عوائق لبعض هذه هـأه الحاجات بحيث تمنع وصول الفرد من الوصول إلى أهدافه مما يشعر الفرد بالإحباط والصراع بين حاجاته ومنطلبات البيئة، فيدفع الفرد إلى السعي الدائم والمكثق للوصول إلى تكيف سليم، فكلما زادت خبرة الفرد بأنماط المجتمع ومتطلباته وتقبلها مال إلى السيطرة على اشباعاته أو تعديلها ويلجأ إلى نشاطات بديلة وإثباع الحاجات الملحة لكي يقوم باستبعاد الصراع من المستوى الثعوري

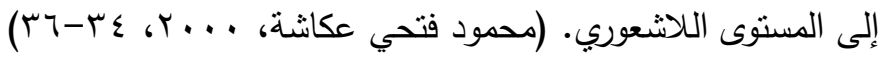
ويتضح من الدراسات السيكولوجية الدختلفة التي تتاولت بالدراسة موضوعات التكيف النفسي والتوافق على أن هناك مستويات متعددة يمكن من خلالها تفسير التوافق وسوء التوافق على أساس أنه متصل يحتل الفرد مواضع مختلفة عليه ومنها: 1- التوافق على المستوى البيولوجي: ويعتدد هذا التوافق على مفاهيم فسيولوجية خاصة

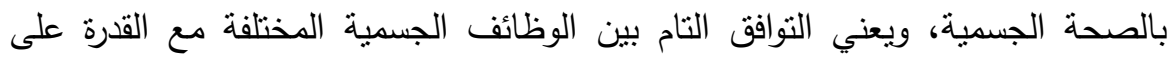

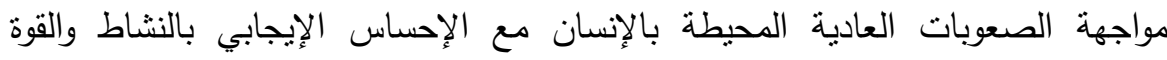

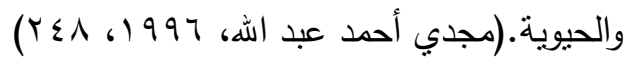

والتوافق في هذا الإطار يعني عملية المحافظة على مستوى الاتزان الداخلي للجسم من طريق تعلم مجموعة من الطرق والأساليب التي تودي إلى تخفيف حدة القلق والتوتر

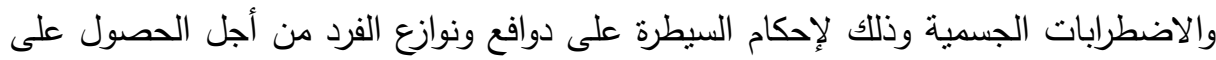

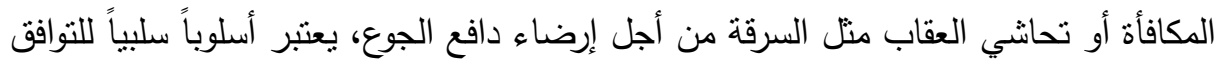

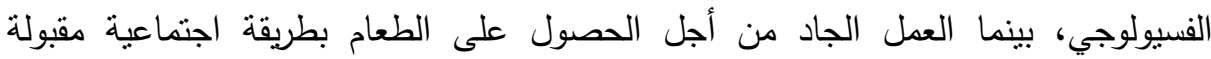

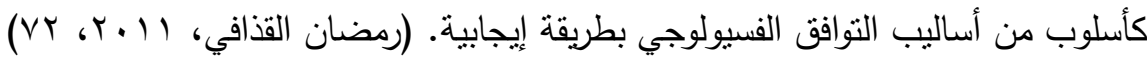

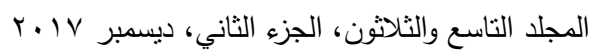


وعلى هذا فإن عملية التوافق يجب أن تتسم بالمرونة والاستمرار المتواصل، وذلك لتغير

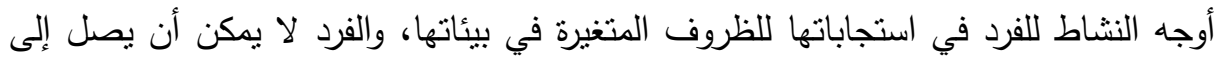

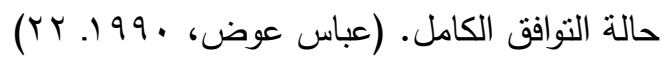
r- التوافق على المستوى النفسي: وهذا يعني أن الصحة النفسية تعني التوافق التام والتكامل بين الوظائف النفسية المختلفة مع القدرة على مواجهة الأزمات النفسية العادية التي تطرأ

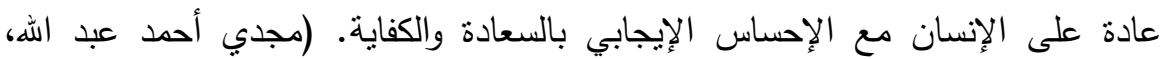
$(r T \wedge, 1997$

ويركز هذا الاتجاه على النظر إلى النفس بشكل واقعي وموضوعي ونقل نقاط القوة والضعف على سواء دون خوف أو اضطراب، ولكن عند حدوث الاضطراب يتولد أنماط السلوك غير التوافقي مما يؤثز على علاقة الفرد بالمحيطين به يصاحب الثعور بالقلق والتوتز

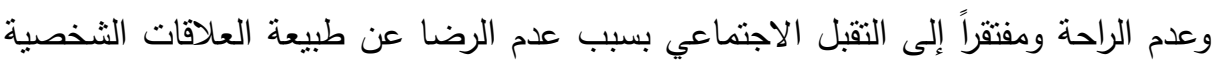

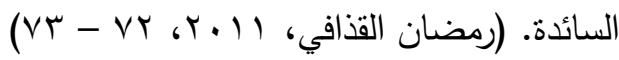

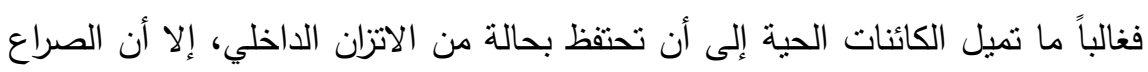

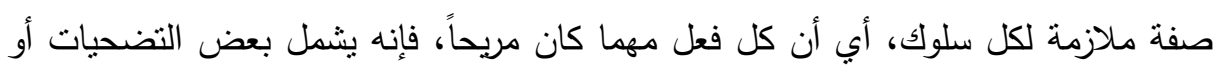

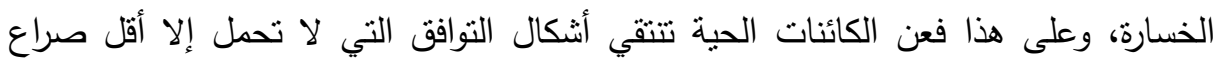
ممكن يؤدي إلى أقصى تكامل، وهذا يشير إلى أن توافق الإنسان يعني التصتع بالنضج

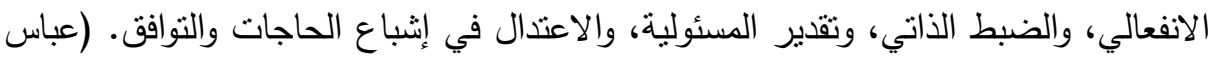

r- التوافق على المستوى الاجتماعي: وينظر هذا الاتجاه إلى عمليات التوافق من خلال

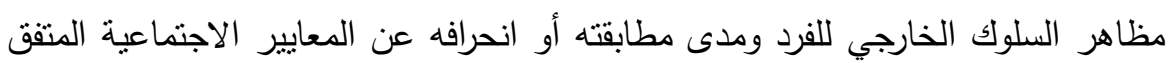

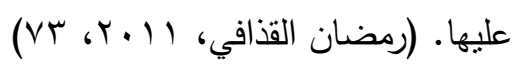

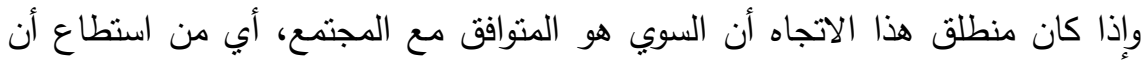

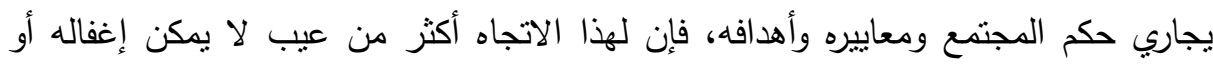

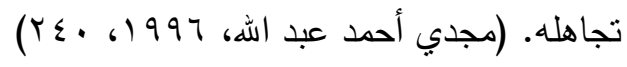

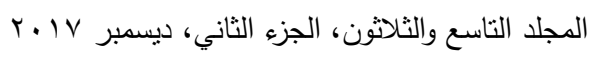


وعلى هذا فإن إحداث تغيير للأحسن في الفرد أو في البيئة فقد يحقق الانسجام بينهما،

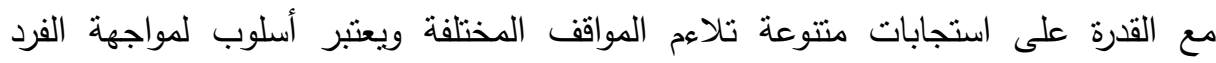

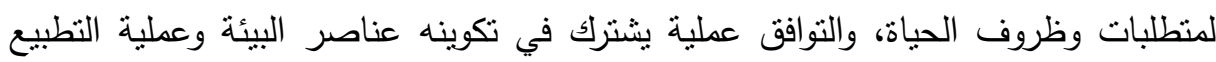

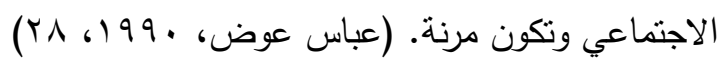
وتركز الدراسة الحالية على النظرة المتكاملة في دراسة التوافق البيئي للفقراء وتتشمل أيضاً

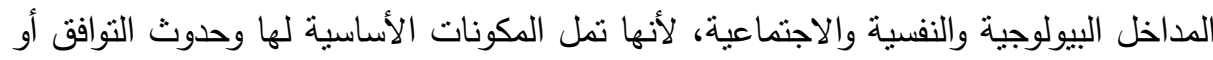
عدم نوافقهما يرجع إلى الأسباب البيئية في التفسيرات السابقة.

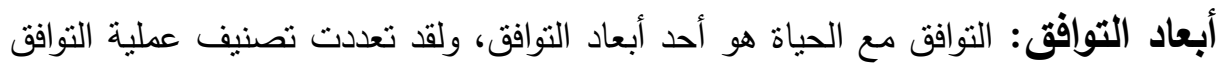
حسب طبيعة الموقف الذي يمر به الفرد فقد أنشارت العديد من الدراسات على أبعاد مختلفة في

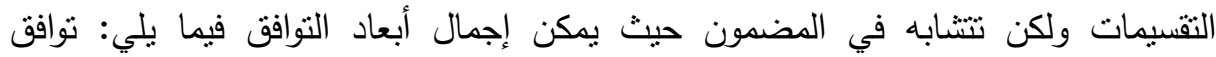
اجتماعي، توافق ديني، نوافق دراسي، نوافق مهني، نوافق منزلي، توافق انفعالي، نوافق

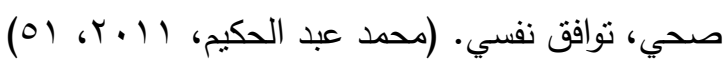
معايير التوافق: بصعب الاتفاق على معايير التوافق، نظراً لارتباط عملية التوافق بالمكان

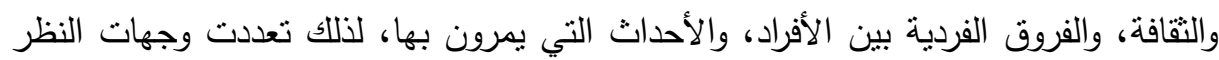

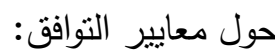

- وجهة النظر الأولى: حدد لازاروس Lazarus أربعة معايير أساسية للنوافق وهي: الراحة النفسية - الكفاية في العمل - الأعراض الجسمية - التقبل الاجتماعي.

(Lazarus, Richard, j. 1993: 555) - وجهة النظر الثانية: المسئولية الاجتماعية للفرد - القدرة على اكتساب المهارات

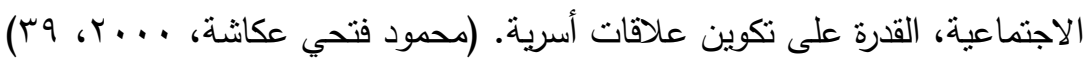

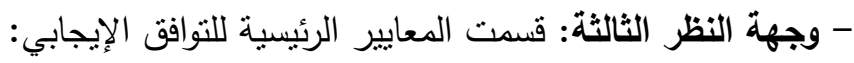
1 - معيار توحد النظرة للحياة: وهو يركز على وظيفة السلوك الذي يقوم به الفرد وما يحققه من أهداف وليس شكل السلوك أو الفعل نفسه، أي أن الشخصية المتكاملة من نواجه مشكلاتها وصراعاتها وليس الهروب منها. 
r - الإدراك الواقعي للأات: هي قدرة الفرد على تحديد احتياجاته والتخطيط بطريقة واقعية ليحقق أهدافها حتى لا يوجه إحباط مشكلات أخرى تنؤدي سوء النوافق.

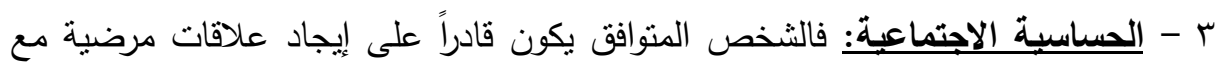
الآخرين، قائمة على التفاهم والاحترام والتقة المتبادلة مع أسرته وجيرانه.

ع - التوانن الدينامي: ويعني التوازن بين القوى الداخلية للسلوك والقوة الخارجية للبيئة بحيث تكون تلك القوى متغيرة باستمرار ومرنه، ويمكن أن نرى الثخص المتوافق من يواجه

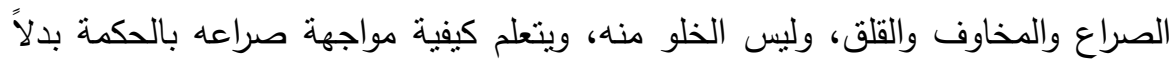
من الثعور بالعداوة الثنديدة أو الانطواء.

ه - النضج الانفعالي: ويعني أن يتحكم الثخص في سلوكه الانفعالي بحيث لا تكون خالياً

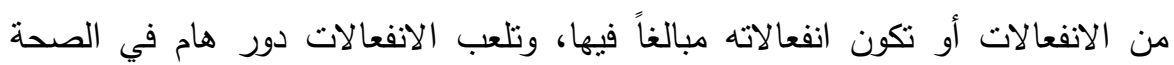
النفسية والجسمية، أما الانفعالات غير المعقولة فهي دليل على الفيل عدم الصحة النفسية.

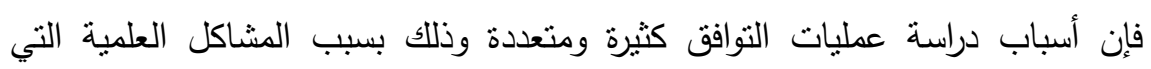
يواجهها الفرد يومياً في صراعه مع متطلبات الحياة، ومن أهم هذه المشاكل هي ارتفاع نسبة ودنة حدوث سوء التوافق بشكل منوسط أو شديد، وهذا ما يعرف بالاضطرابات النفسية والعقلية في

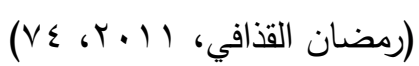
كما تهدف عملية التوافق إلى تماسك شخصية الفرد ومواجهة الأزمات النفسية مما بؤدي

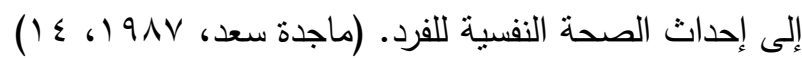
كما أن عملية التوافق لها تأثير على شعور الفرد بالارتياح والرضا على تلبية احتباجاته،

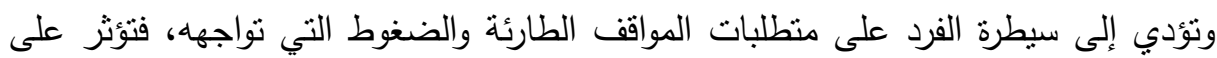

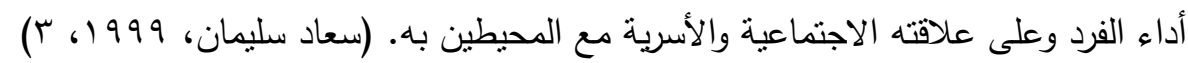
وفي حالة عجزه عن التكيف مع نفسه، ومن خلال تتظيم إثباع دوافعه في إطار ما يقره المجتمع من قيم ومبادئ وقوانين، والتوفيق بين إمكانياته وتطلعاته مع البيئة المحيطة بهاه،

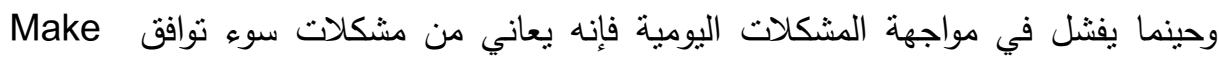

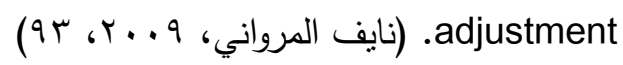




\section{منهجية التراسة}

نوع الدراسة: ندخل هذه الدراسة بحكم موضوعها واهتمامها فى إطار الدراسات الوصفية، من هنا كان هذا النوع من الدراسات أكثر ملائمة لهذا البحث، حيث تسعى الدراسة الحالية لوصف أوضاع الفقراء وكيفية نوافقهم البيئى.

المنهج والأدوات المستخدمة فى جمع البيانات: المسح الاجتماعي وذلك لاستقراء الواقع الاجتماعي( المنهج الوصفى) وتحليل المشكلة تحليلاً إيكولوجياً كما هي قائمة بالفعل بما يوفره هذا المنهج من فيها، وكذلك إعطاء صورة واضحة عن نوعية الحياة بها، بما

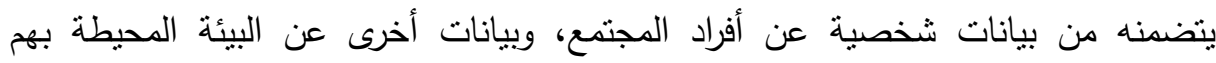

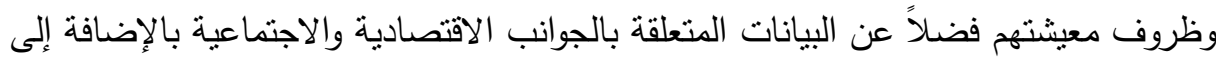

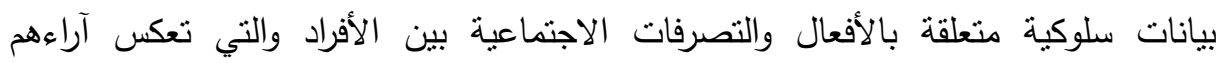
واتجاهاتهم ونوافقهم الاجتماعي والنفسي نحو قضية الفقر التي يعانون منها.

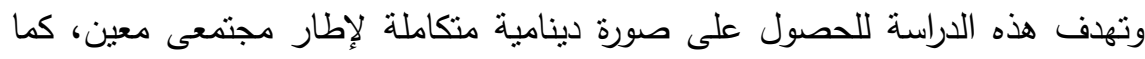

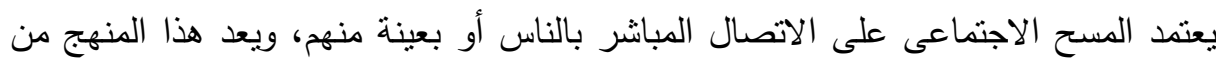

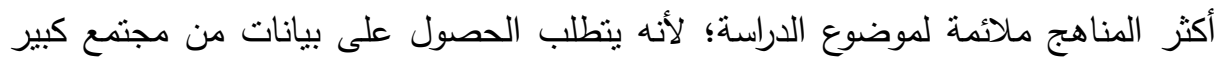

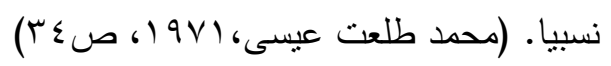
وقا قامت الباحثة بتصميم المقياس الذى يتوافق مع أهداف وتساوّلات وفروض الداسة

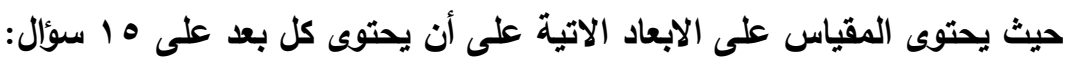

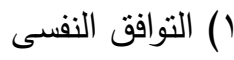

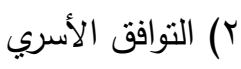

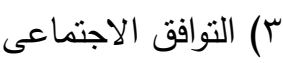
ع) التوافق مع البيئة الفيزيقية

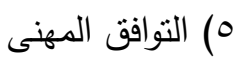




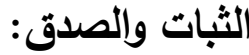

ثبات المقياس: للتحقق من ثبات المقياس استخدم الباحثة معادلة ألفا كرونباخ (A) Cronbach) Alpha)، ويوضح الجدول النالي معاملات الثبات الناتجة باستخدام هذه المعادلة. جدول رقم(1): ثبات العبارات لأبعاد مقياس التوافق البيئي

\begin{tabular}{|c|c|c|}
\hline قيمة آلفا & عدد العبارات & آبعاد المقياس \\
\hline$\cdot, \vee \backslash \wedge$ & 10 & البعد الأول :التوافق النفسي \\
\hline$\cdot, \wedge \circ \wedge$ & 10 & البعد الثاتي :التوافق الأسرى \\
\hline$\cdot, V \cdot 7$ & 10 & البعد الثالث :التوافق اجتماعيا \\
\hline$\cdot, V \vee Y$ & 10 & لبعد الرابع :التوافق مع البيئة الفيزيقية \\
\hline$\cdot, 9 \lambda 1$ & T乏 & البعد الخامس :التوافق المهني: \\
\hline$\cdot, 911$ & $V \varepsilon$ & الدرجة الكلية لمقياس التوافق \\
\hline
\end{tabular}

يتضح من الجدول السابق أن قيم معاملات الثبات لأبعاد مقيساس التوافق البيئي قيم

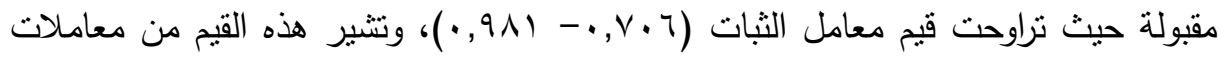

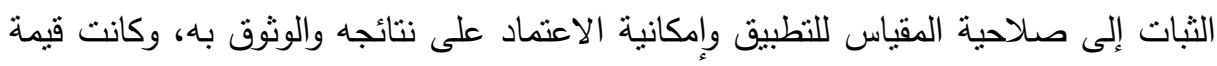
ألفا لإجمالي المقياس (1) (919, •) وهي قيمة مرتفعة. صدق الإتساق الداخلي للمقياس: نم حساب معاملات ارتباط كل بعد من أبعاد المقياس بالدرجة الكلية للمقياس والتي نتجت عن تطبيق المقياس على عينة مبدئية بلغ عدد أفرادها (•) فرد من أفراد عينة الدراسة، وقامت الباحثة بحساب صدق الإتساق الداخلي كالآتي: جدول رقم(r): صدق الاتساق الداخلي لأبعاد مقيـاس التوافق البيائي

\begin{tabular}{|c|c|c|}
\hline إجمالى مقيــاس & & آبعاد المقياس \\
\hline "***, rVV & معامل ارتباط بيرسون & \multirow{2}{*}{ البعد الأول: التوافق النفسي } \\
\hline$\cdot, \ldots$ & الدلالة المعنوية & \\
\hline$*, \vee \vee \neg \varepsilon$ & معامل ارتباط بيرسون & \multirow{2}{*}{ البعد الثاتي: التوافق الأسري } \\
\hline$\cdot, \cdot Y$ & الدلالة المعنوية & \\
\hline ***, rTr & معامل ارتباط بيرسون & \multirow{2}{*}{ البعد الثالث :التوافق اجتماعيا } \\
\hline$\cdot, \cdots$ & الدلالة المعنوية & \\
\hline$* *, 17 r$ & معامل ارتباط بيرسون & \multirow{2}{*}{ لبعد الرابع :التوافق مع البيئة الفيزيقية } \\
\hline$\cdot, \cdots$ & الدلالة المعنوية & \\
\hline$* *, \wedge 91$ & معامل ارتباط بيرسون & \multirow{2}{*}{ البعد الخامس :التوافق المهنى: } \\
\hline$\cdot, \ldots$ & الدلالة المعنوية & \\
\hline
\end{tabular}


من جدول صدق الاتساق الداخلي السابق لمقياس التوافق البيئي نجد أن معامل ارتباط

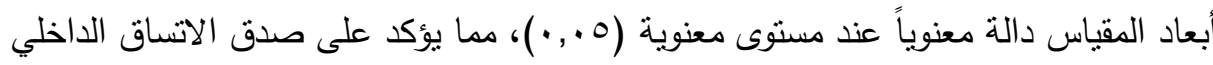

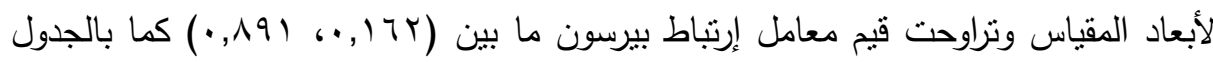
أعلاه وهي قيم تؤكد على صدق المقياس.

\section{مجالايت الكراسلة}

المجال المكانى: قامت الباحثة بأجراء الدراسة الميدانية من خلال ثلاثة أحباء ممثلة لمجتمع

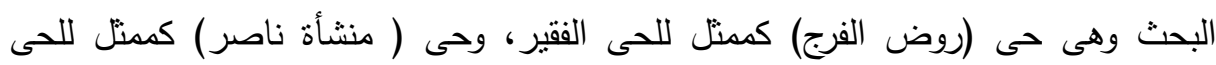

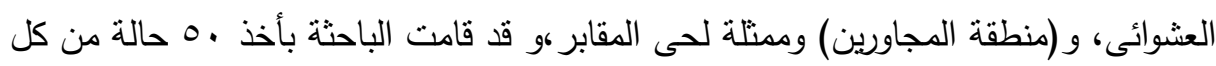
منطقة منهم، وكلا من الثناث مناطق داخل نطاق مدينة القاهرة.

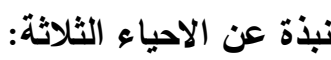

أ- منشأة ناصر: الموقع : نقع منشأة ناصر بداخل جبل المقطم غرب مدينة نصر ووشمالا منطقة الزبالين و الى الجنوب المقابرو الى الثرق منطقة القلعة، حيث يفصلها عنهما

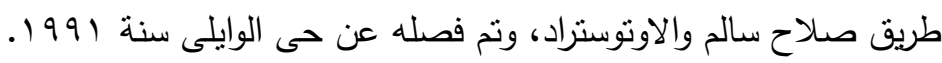

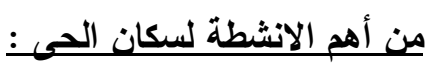

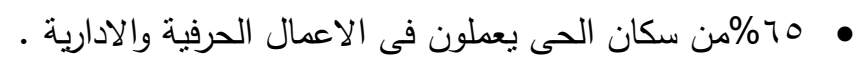

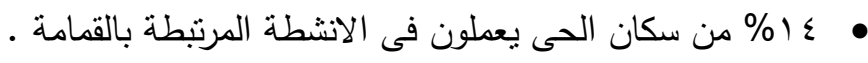

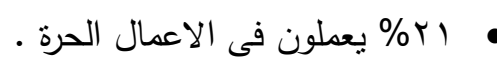

بيانات أساسبة :

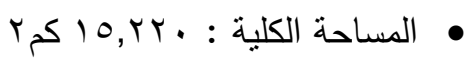
• • • • • • • •

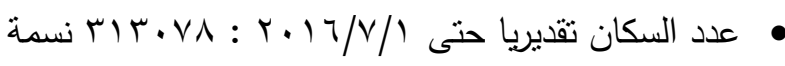




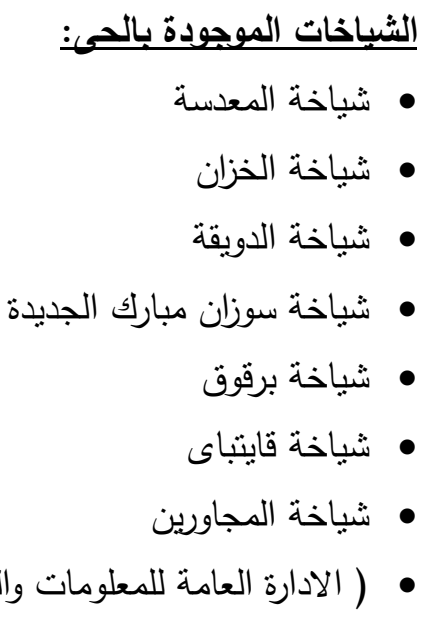

ب) حى روض الفرج: يعتبر حى روض الفرج أحد أحياء شمال القاهرة، وهو حى شعبى قديم، كان قديما للمسارح كما كان يطلق عليها ومنه انطلق الكثير من الفنانين الاستعراضين

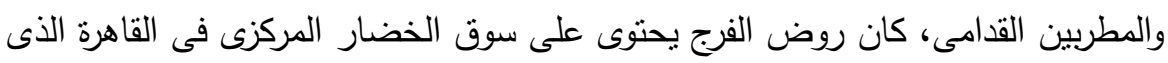
كان بمثابة مركز تجميع من جميع أنحاء الجمهورية، الا أنه نم نقله الى مدينة العئة العبور

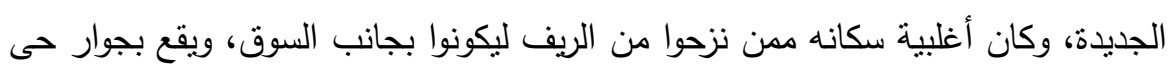

شبرا ويختص بقسم للشرطة، وبه منطقة "جزيرة بدران".

بيانات أساسبة:

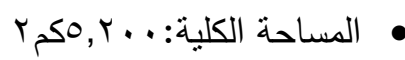

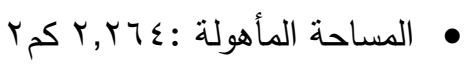

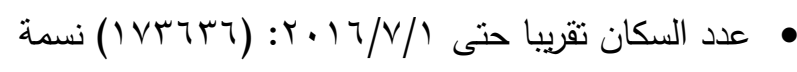
الحدود الادارية للحى:

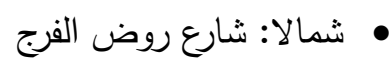

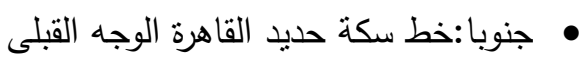

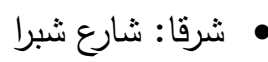

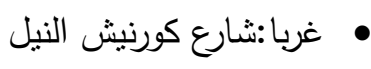


ج- مقابر المجاورين: مقابر المجاورين واحدة من المقابر التى تقع فى قلب المناطق السكنية

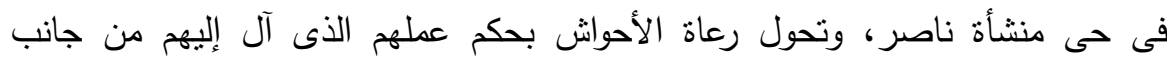

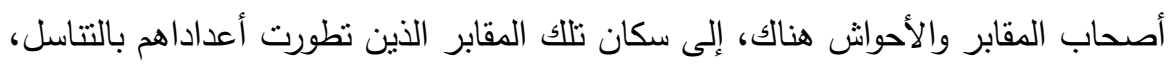
وزواج هذه الأنسال فيما بعد لتكون أسرا جديدة، وهناك من يسقط حقه فى الحصول على لهى

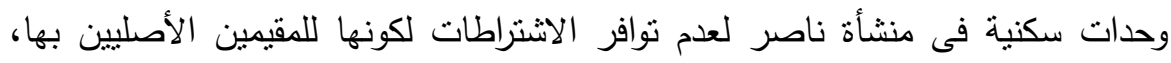
فيلجأون إلى الإقامة داخل تللك المقابر وسط كافة الأهوال والمخاوف التى تحيط بنلك لكان

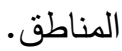
وداخل مقابر المجاورين يقطن السكان هناك منذ ما يزيد على الخمسين عاما بحسب

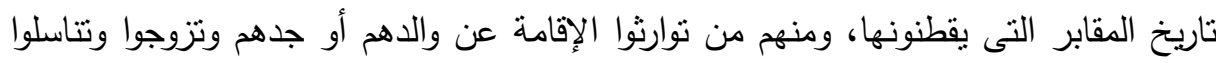
لتستمر حياتهم داخل المقابر وكذلك الاستمرار فى خدمة تلك المقابر وحراستها. المجال البشرى: يتمنل المجال البشرى للاراسة الحالية من عينة نبلغ (10) حالة من الذكور والاناث الفقراء الذين يتحايلون على المعيشة لكى يستمروا فى البقاء، والذى سيتم تطبيق كلا من استمارة الاستبيان والمقياس عليهم. المجال الزمنى: استغرقت الدراسة حوالى ثلاث سنوات بدأت بجمع الدراسات السابقة والجزء

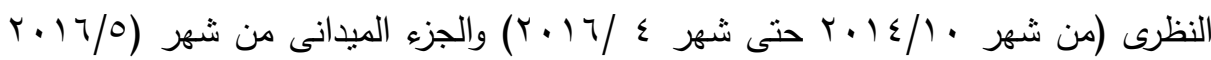

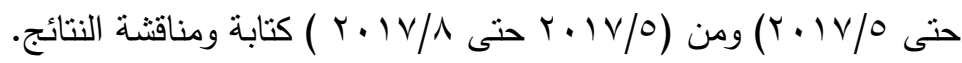




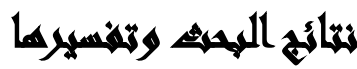

() توجد فروق إحصائية ذات دلالة معنوية بين عينة الدراسة (ساكني المقابر/حي عشوائي) لكقياس التوافق البيئي. جدول رقم(r): اختبار (ت) T-Test لتوضيح الفروق بين عينة الدراسة لمقياس التوافق

\begin{tabular}{|c|c|c|c|c|c|}
\hline & & & & & \\
\hline المعنوية & قيمة ت & الأمعياري & | المتوسط | & العينة & المتغيرات \\
\hline \multirow{2}{*}{ 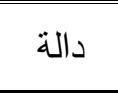 } & \multirow{2}{*}{$r, T \leqslant V$} & $\varepsilon, \Gamma \varphi$ & $r \varepsilon, \Lambda$ & ساكنى المقابر & \multirow{2}{*}{ البعد الأول :التوافق النفسي } \\
\hline & & r, & $T V, T \varepsilon$ & حى عشوائى & \\
\hline \multirow{2}{*}{ غير دالة } & \multirow{2}{*}{$\cdot, 900$} & $0, Y_{1}$ & $r \cdot, v$ & ساكنى المقابر & \multirow{2}{*}{ البعد الثاتي :التوافق الأسري } \\
\hline & & $0, \cdot \varepsilon$ & $\Gamma, 7 \Lambda$ & حى عشوائى & \\
\hline \multirow{2}{*}{ 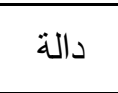 } & \multirow{2}{*}{$r, 1 q^{\prime}$} & $T, \wedge \varepsilon$ & $r \cdot r r$ & ساكنى الدقابر & \multirow{2}{*}{ البعد الثالث :التوافق اجتماعيا } \\
\hline & & Y,OY & $T \wedge, T \varepsilon$ & حي عشوائي & \\
\hline \multirow{2}{*}{ 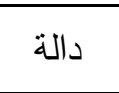 } & \multirow{2}{*}{$9,0 Y V$} & r r & YY, $\varepsilon$ & ساكنى المقابر & \multirow{2}{*}{ البعد الرابع :التوافق مع البيئة } \\
\hline & & $Y, 01$ & $r \cdot, V \wedge$ & حي عشوائي & \\
\hline \multirow{2}{*}{ 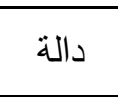 } & \multirow{2}{*}{$r, 0 . r$} & 4,19 & $T \varepsilon, V \varepsilon$ & ساكنى المقابر & \multirow{2}{*}{ البعد الخامس :التوافق المهنى } \\
\hline & & $1, \vee \wedge$ & $T r, V \varepsilon$ & حي عشوائي & \\
\hline \multirow{2}{*}{ دالة د مالة } & \multirow{2}{*}{$r, \varepsilon \leqslant 1$} & $\Lambda, Y Y$ & 1147,97 & ساكني المقابر & \multirow{2}{*}{ الدرجة الكلية لمقياس التوافق } \\
\hline & & $1,, .0$ & $I M Y, \Sigma \Lambda$ & عشوائى & \\
\hline
\end{tabular}

الوصف: من الجدول السابق لتوضيح الفروق بين عينة الدراسة ( لساكنى المقابر، والحى العشوائى) لمقياس التوافق البيئى اتضح الآتى: لونى لوضئ البعد الاول: التوافق النفسى: وجود علاقة ذات دلالة معنوية عند مستوى معنوية (0., •) بين

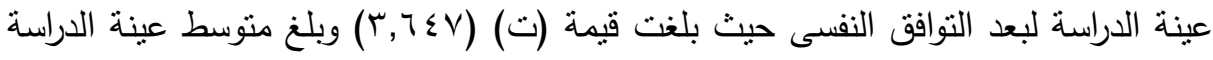

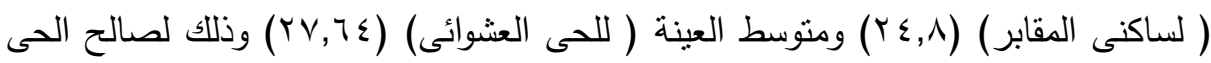
العشوائى.

البعد الثانى: التوافق الاجتماعى: وجود علاقة ذات دلالة معنوية عند مستوى معنوية

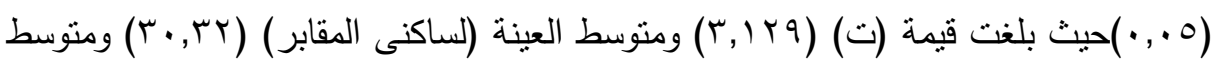

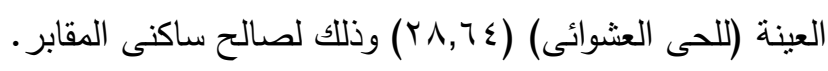


البعد الثالث: التوافق مع البيئة الفيزيقية: وجود علاقة ذات دلالة معنوية عند مستوى معنوية

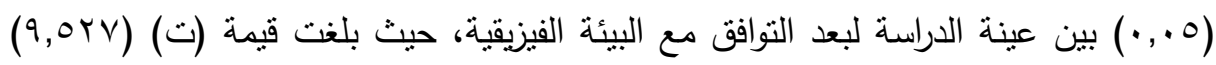

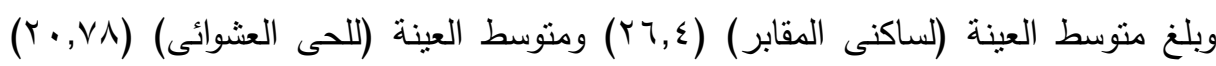
وذللك لصالح ساكنى المقابر • البعد الرابع: التوافق المهنى: وجود علاقة ذات دلالة معنوية عند مستوى معنوية(0. ., •) بين

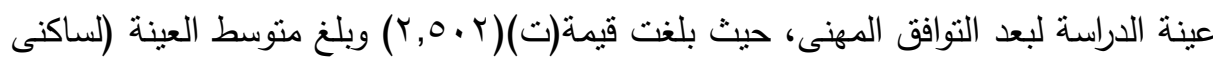

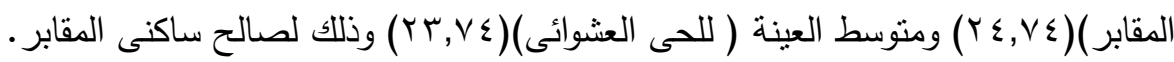
الارجة الكلية لمقياس التوافق: وجود علاقة ذات دلالة معنوية عند مستوى معنوية(ه ., •)

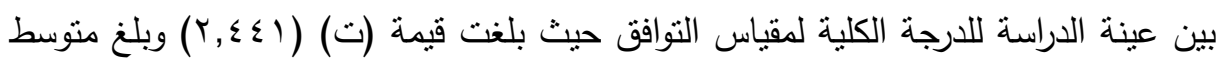

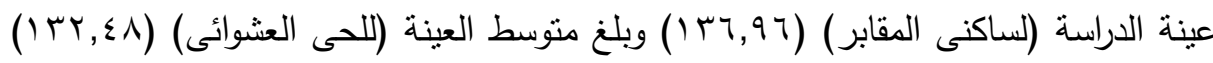
وذللك لصالح ساكنى المقابر • بينما لا نوجد علاقة ذات دلالة معنوية عند مستوى معنوية (0., •)بين عينة الدراسة

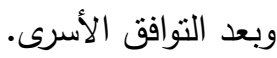

التفسير: اتضح من خلا هذه الدراسة أن هناك فروق دالة بين كلا من ساكنى المقابر والحى العشوائى للتوافق النفسى فيشعر كلا منهما بتقلب المزاج، والفشل بدون سبب، والاحباط المتكرر ،و عدم الثقة بالنفس، والاصابة باليأس، والثعور بالوحدة والعزلة، والثعور بالتوتر لئن

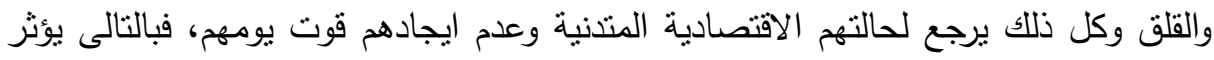

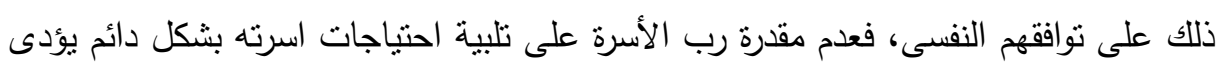

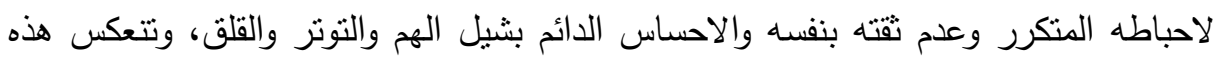

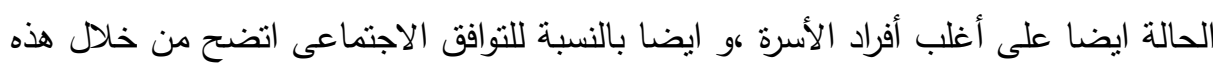

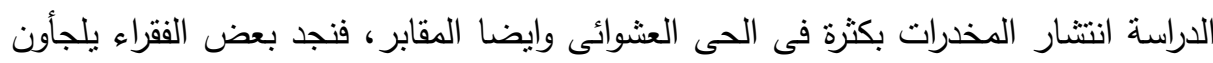

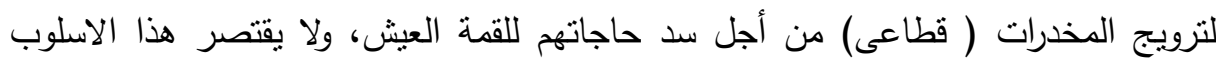
على الرجال فقط، بل تمارسه النساء ايضا، وعلى الرغم من وجود سبل متعددة ومنتشرة

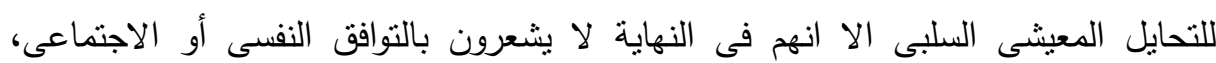

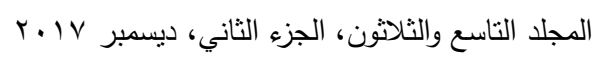


وبالنسبة للجرائم السلوكية نجد أنها تتتشر فى الاحياء الثلاثة، فنجد أغلب اهالى هذه الطبقة

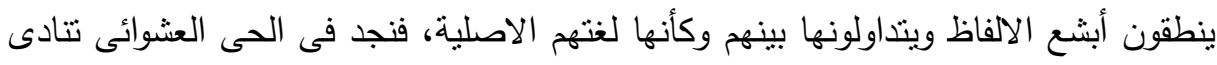

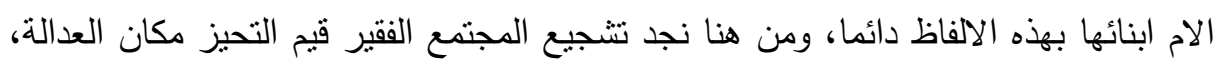
والمواربة مكان الصراحة ،و التتكك مكان الثقة، والفهلوة مكان الجدية، وكل ذلك تغرسه التهان الأسرة الفقيرة فى اطفالها من قيم القسوة وانتهاز الفرص والاخذ بحق أو بغير حق، ونجد أن هذه اله

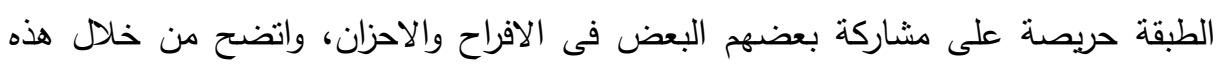

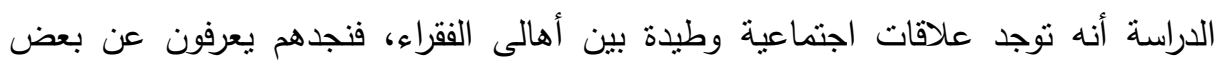

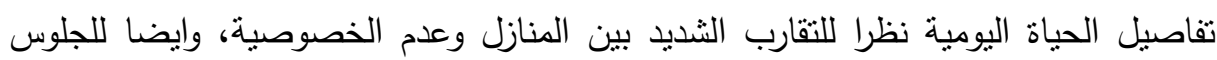

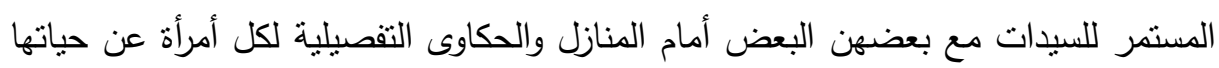

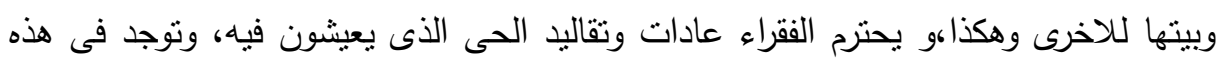
الاحياء بعض المجموعات الاجرامية وسوف نعرضها كالتالى:

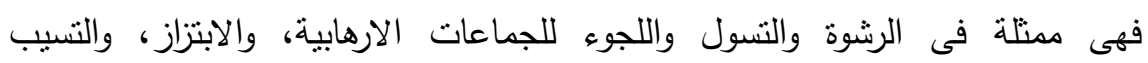
الاخلاقى، وتجارة المخدرات. الرشوة: كنا نتحدث قديما على كبار الموظفين المرتتين والذين برأسون بعض الوظائف

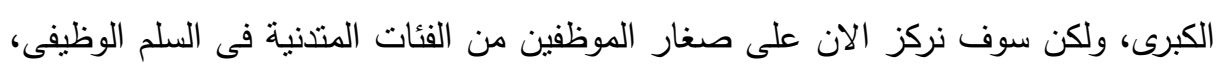

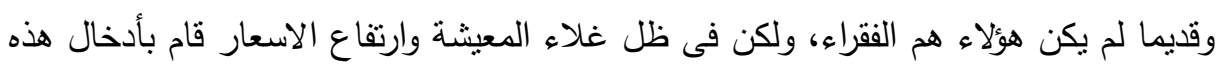

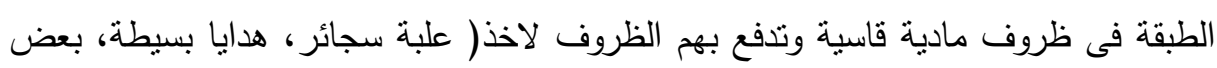

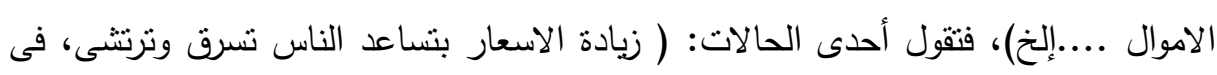

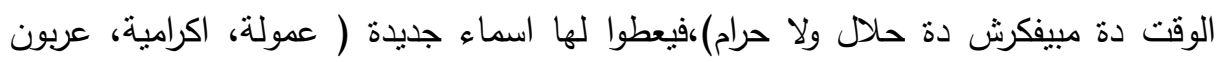
التسول: تعد ظاهرة التسول منتشرة جدا بين هذه الطبقة، فهى تتميز أن جميع الفئات العمرية

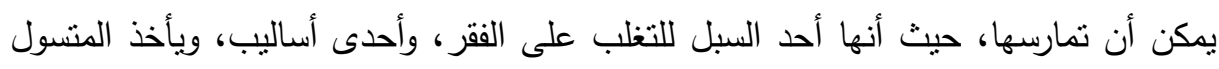
طريقتين اسلوب الثحاتة من الجيران، واسلوب التسول فى الثورع. 
اللجوء الى التطرف: اتضح من خلال هذه الدراسة والدراسات السابقة، ان الفقراء يلجأون لهذه

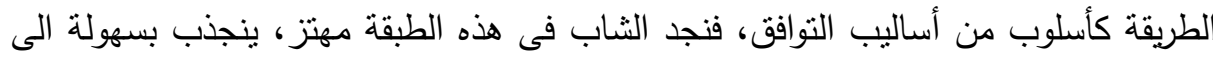

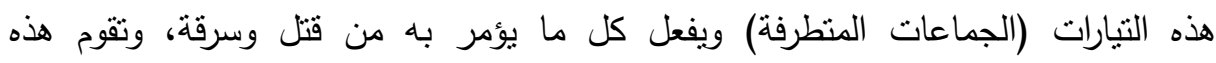
الجماعات بأستغلال هؤلاء الثباب فى صالح الجماعة دائما. السرقة: يمارس الاطفال والكبار (الرجال والنساء) السرقة فى الاماكن المزدحمة دأعاء مثل

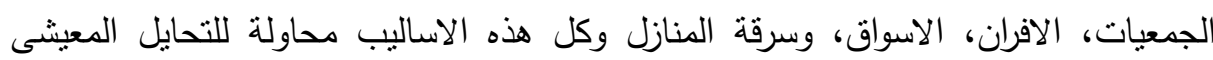
والتكيف السلبى لهم.

الابتزاز: قد تختلط الامور بالنسبة للفقراء فى موضوع الملكية، فأن تمكنوا من تحويل ملكية عامة إلى خاصة كان ذلك أفضل، كتوصيل الكهرباء من أحدى الاعمدة فى الثنارع لبيته . التسيب الاخلاقى: تلجأ بعض الفتيات فى ظل الفقر إلى ممارسة الرذيلة مقابل الاموال

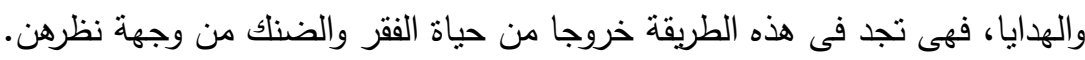
ترويج المخدرات: يلجأ بعضق الفقراء إلى ترويج المخدرات من أجل سد احتباجاتهم إلى لقمة فئة

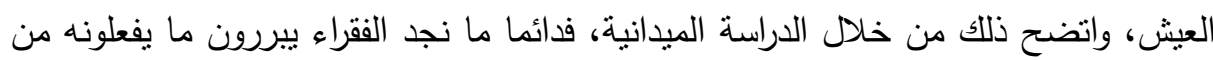
نشاط غير قانونى ليتغلبون على ظروفهم ويتعايثوا.

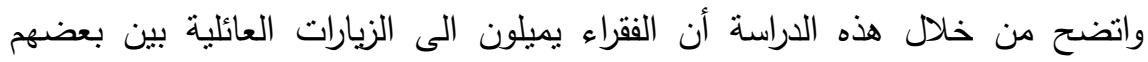

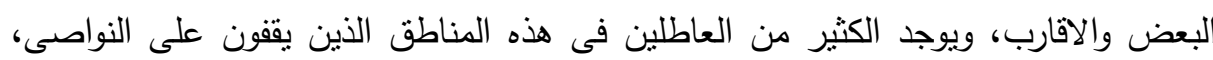

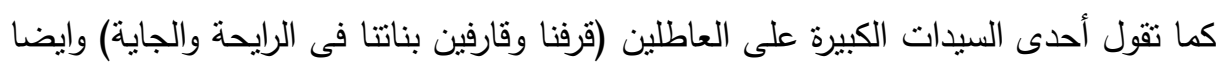
أغلبهم ممن يبيع المخدرات بالتجزئة . وينطبق هذا مع نظرية ثقافة الفقر لاوسكار لويس: حيث يوضح أوسكار لويس أن الفقر

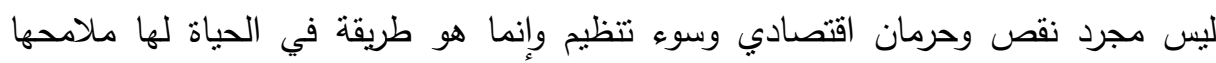

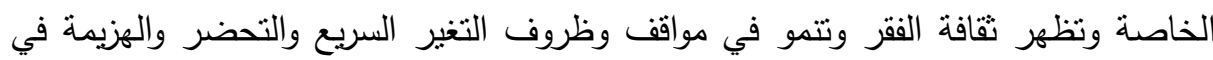

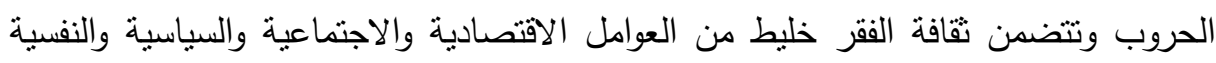

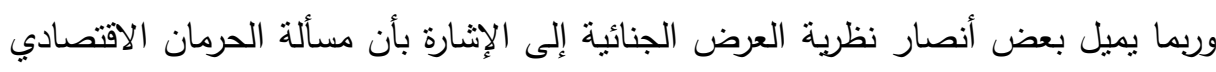


لها تأثيراتها القوية كدافع لارتكاب الجريمة، فهذا الحرمان يدفع الفقراء إلى شعورهم بالمهانة من قبل المجتمع مما يكون حافزاً لديهم لارتكاب الجريمة كإجراء انتقامي. وأيضا ينطبق مع ( الددرسة السلوكية) فيقول( واطسون) مقولته الثهيرة (اعطنى دستة لابنة من الاطفال فسوف اصنع منهم ما أريد مهندسين واطباء وقضاه أو مجرمين ولصوصنه الصنه فالفرد صفحة بيضاء، والمجتمه يشكله من خلال عملية التنشئة الاجتماعية فى البيت والمدرسة وينمى فيه الحاجات والاهداف التى مع تقاليده وقيمه. التوافق مع البيئة الفيزيقية: تنقارب المساكن جدا فى المناطق العشوائية وكأنهم يعيشوا مع بعض، لا نوجد خصوصية، اذا فتح احداهما الثباك يسلم على جاره، وتعتبر هذه البيوت مجال شائع للسرقة لقربها من بعضها، وتتقطع الكهرباء فى هذه المناطق بين الحين والاخر

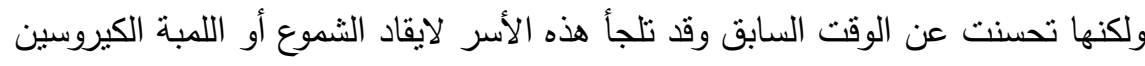

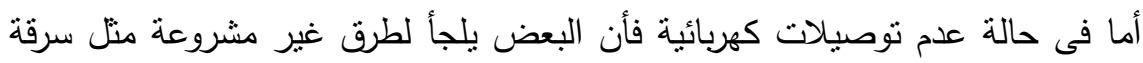

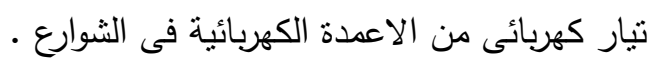
أقر أغلب حالات الدراسة سواء فى الحى العشوائى أو الدقابر أنهم لا يستطيعوا استتشاق

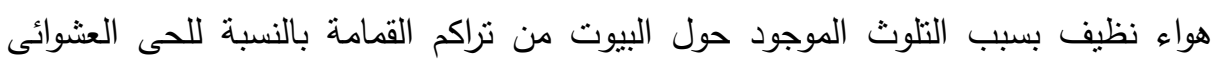

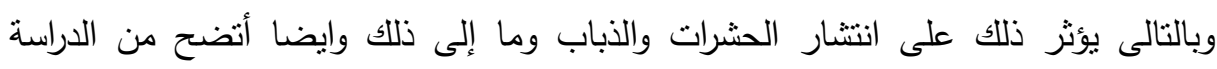

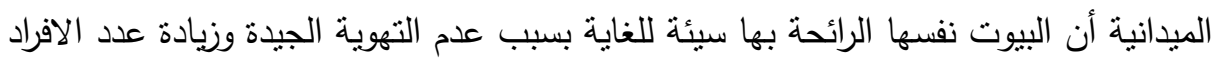
الذين يعيشوا فى غرفة واحدة واستخدام نفس الغرفة لاغراض الطبخ وفى بعض الغرف لانه لا يوجد

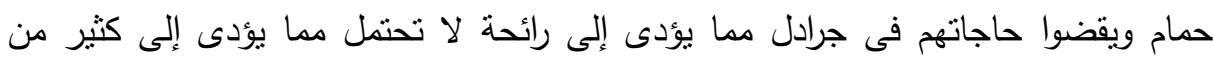
الامراض، واتضح ايضا من دراسة حى المقابر أن رائحة الميت تكون سيئة بعد دفنه بأيام فتقول أحدى الحالات ( أنا بسيب البيت وأمشى اروح اقعد انا وبنتى عند أبنى المتجوز أول

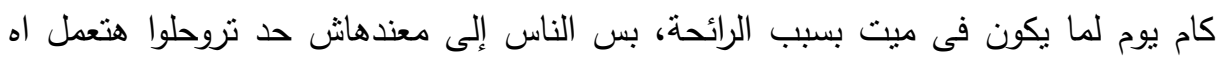

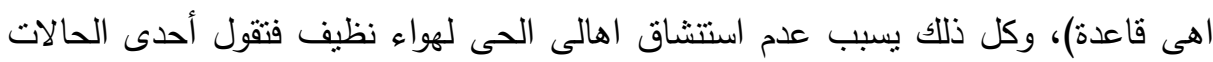
(احنا بنشم رائحة ميتين وناس نانية بنشم كلونيات). 
اتضح من خلال الدراسة الميدانية أنه مازالت هناك أزمة فى المياه حتى الان فنقطع

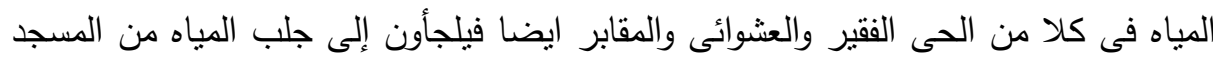
فى الثارع، واحيانا تكون المياه ضعيفة لا تصل للادوار العليا، فيلجأ الاهالى إلى ملى المياه

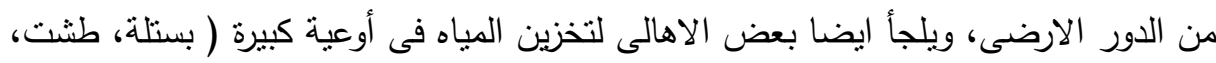

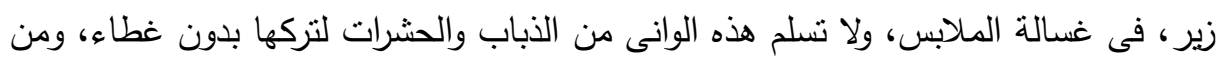

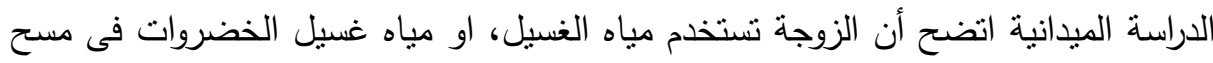

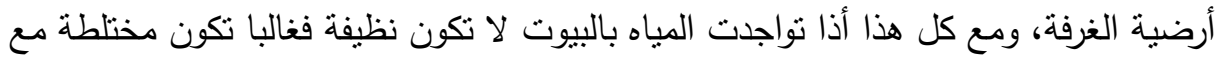

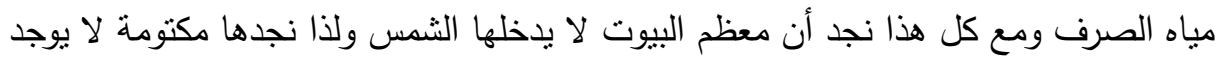

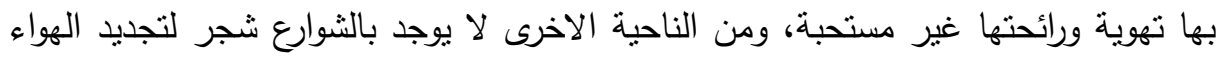
دائما ولكن توجد القمامة بكميات كبيرة.

النظافة: لعب الفقر دورا كبيرا فى عدم خصوصية الملابس والادوات، فتستخدم الملابس الداخلية بين الاطفال أو بين البالغين من ذكور واناث مما يؤدى إلى تلوث الملابس وانتقال

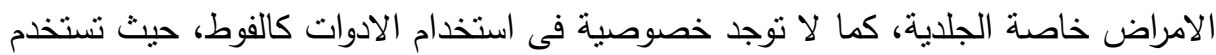

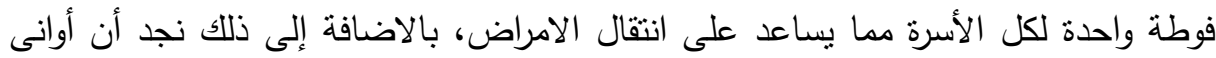

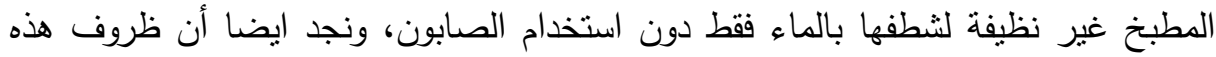
الأسر النى تستخدم مراحيض مشتركة بين عدة غرف يجعل المرحاض غاية فى التلوث

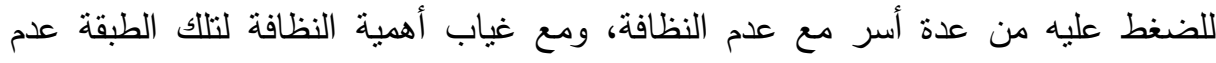
غسيل الايدى قبل الاكل مما بسبب الكثير من الامراض وخاصة بالنسبة للاطفال الذين

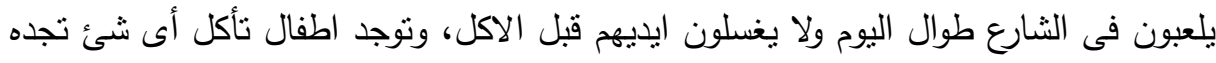

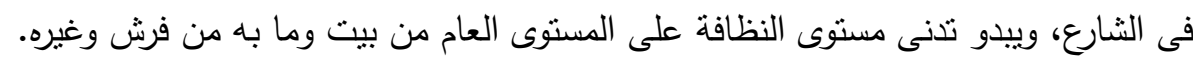

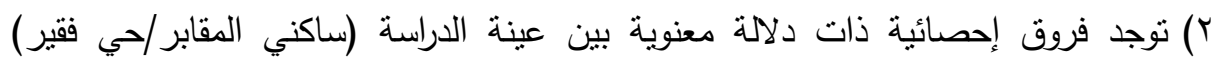
لمقياس التوافق البيئي. 
جدول رقم(؛): اختبار (ت) T-Test لتوضيح الفروق بين عينة الدراسة لمقياس التوافق

\begin{tabular}{|c|c|c|c|c|c|}
\hline & & & & & 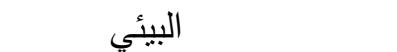 \\
\hline المعنوية & قيمة ت & الإنعياريف & | المتوسط & العينة & المتغيرات \\
\hline \multirow{2}{*}{ 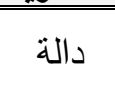 } & \multirow{2}{*}{$\begin{array}{c}- \\
-\varepsilon, O r \xi\end{array}$} & $\varepsilon, \Gamma 4$ & $\varepsilon, \Lambda$ & ساكنى المقابر & \multirow{2}{*}{ البعد الأول :التوافق النفسي } \\
\hline & & $T, Y \mu$ & $r V, q \leq$ & حى فقير & \\
\hline \multirow{2}{*}{ 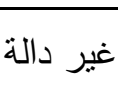 } & \multirow{2}{*}{$\cdot, 7 \leqslant \Lambda$} & $0, Y_{1}$ & $r \cdot, V$ & ساكنى المقابر & \multirow{2}{*}{ البعد الثاتي :التوافق الأسري } \\
\hline & & $\varepsilon, \mu Y$ & $r \cdot, \cdot \Lambda$ & حي فقير & \\
\hline \multirow{2}{*}{ 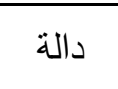 } & \multirow{2}{*}{$r, 1 \wedge 1$} & $r, \wedge \varepsilon$ & $r \cdot, r T$ & ساكنى المقابر & \multirow{2}{*}{ البعد الثالث :التوافق اجتماعيا } \\
\hline & & $Y, Y Y$ & $r \wedge, V$ & حي فقير & \\
\hline \multirow{2}{*}{ دالة } & \multirow{2}{*}{$11, \cdot$} & 每 & YY, & ساكنى المقابر & \multirow{2}{*}{ البعد الرابع :التوافئ مع البيئة } \\
\hline & & $1, Y \wedge$ & $r \cdot, \wedge \varepsilon$ & حي فقبر & \\
\hline \multirow{2}{*}{ غير دالة } & \multirow{2}{*}{$1,0 \mathrm{rV}$} & $r, 19$ & $T \leqslant, V \leqslant$ & ساكنى المقابر & \multirow{2}{*}{ البعد الخامس :التوافق المهنى } \\
\hline & & $1, \wedge \mu$ & $T \varepsilon, I T$ & حى فقير & \\
\hline \multirow{2}{*}{ دالة ل } & \multirow{2}{*}{$r, \varepsilon r \leq$} & $\Lambda, Y Y$ & $1+7,97$ & ساكنى المقابر & \multirow{2}{*}{ الدرجة الكلية لمقياس التوافق } \\
\hline & & $V, I V$ & $\mid \pi, 7 \wedge$ & & \\
\hline
\end{tabular}

من الجدول السابق لاختبار (ت) لتوضيح الفروق بين عينة الدراسة لابعاد مقياس التوافق

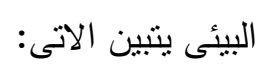

البعد الاول: التوافق النفسى: وجود فروق ذات دلالة معنوية عند مستوى معنوية (0., •) بين

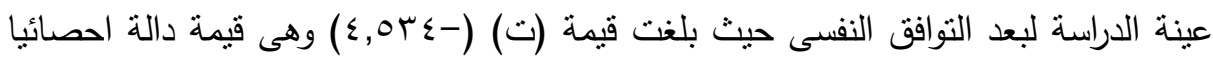

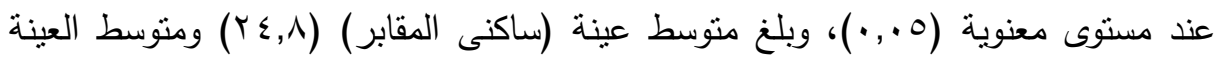

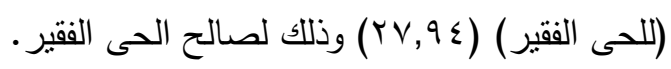

البعد الثانى: التوافق الاجتماعى: وجود فروق ذات دلالة معنوية عند مستوى معنوية

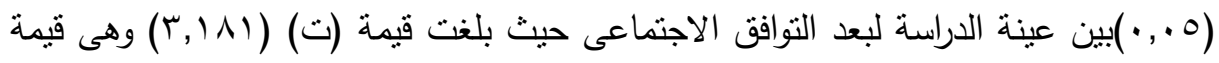

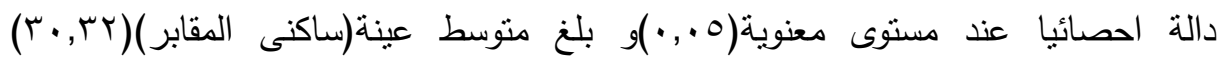

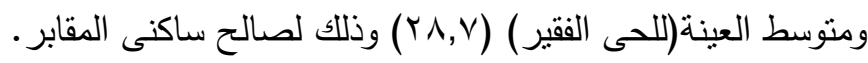

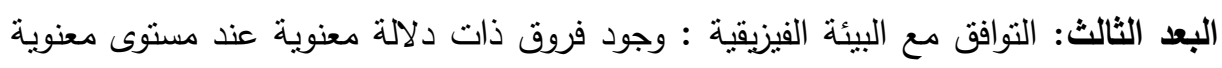

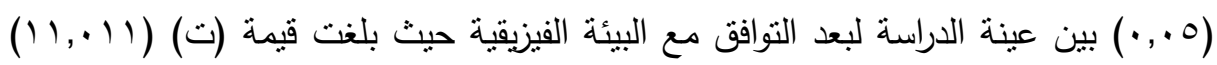


وهى قيمة دالة احصائيا عند مستوى معنوية (0.,.) وبلغ منوسط عينة (ساكنى

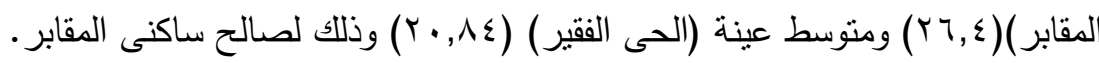
الدرجة الكلية لمقياس التوافق: وجود فروق ذات دلالة معنوية عند مستوى معنوية (0. . •)

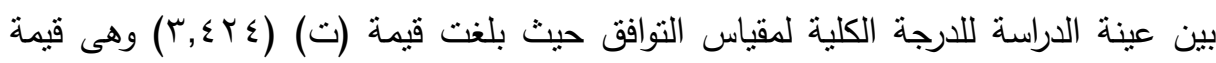

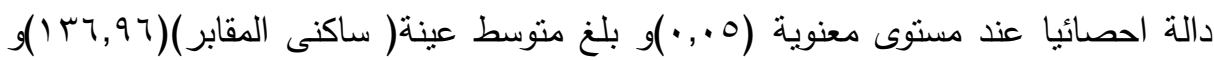

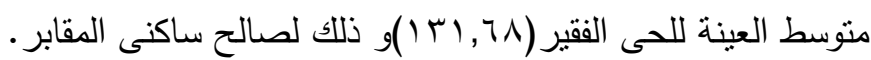
بينما لم يكن هناك فروق ذات دلالة معنوية عند مستوى معنوية (0.,.•) بين عينة

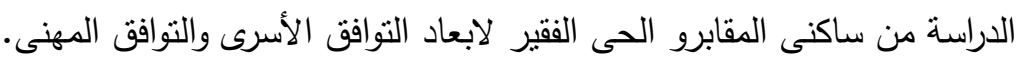
التفسير:التوافق النفسى: اتضح من الدراسة الميدانية أن ساكنى المقابر أقل توافق نفسى من الحى الفقير وذلك لما يتعرضون لحياة صعبة تميل إلى الكأبة إلى حد ما، فعلى الرغم من

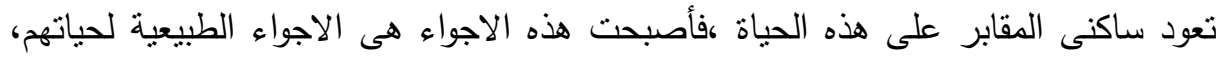

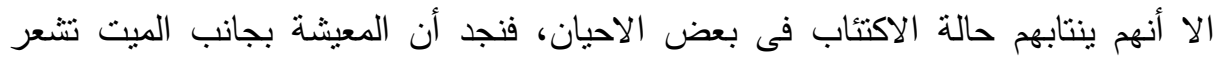

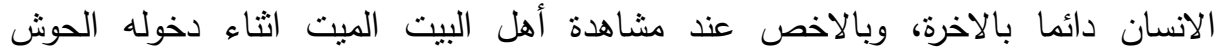
والاصوات العالية اثثاء الدفن(الصويت)كل هذا يؤثر على الحالة النفسية للفرد المقيم بالحوش، وعلى الرغم من أن التوافق النفسى لساكنى الحى الفقير ايضا قليل ولكنه افضل عند المقارنة

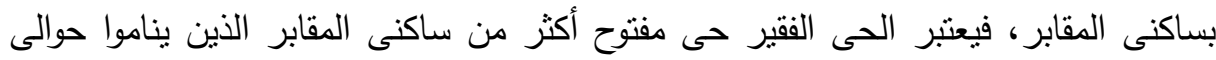

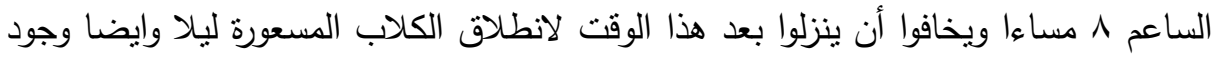

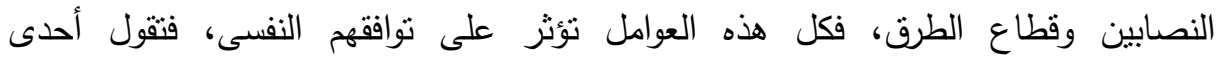

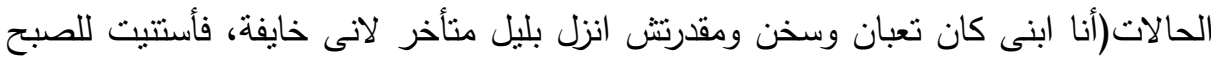

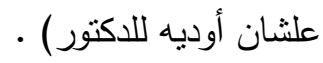
البعد الثانى: التوافق الاجتماعى: اتضح من خلال الدراسة الميدانية أن هناك نوافق اجتماعى لساكنى المقابر أكثر من التوافق الاجتماعى للحى الفقير، فساكنى المقابر يمتازوا بدرجة من القرب كبيرة بينهم وبين بعض، ويتضح ذلك من خلال علاقات الجيرة، فنجدهم

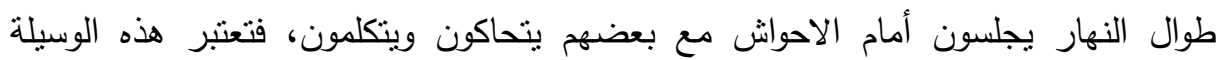

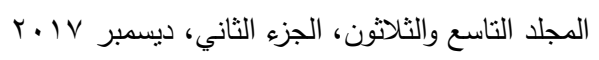


الوحيدة بالنسبة لهم للتفريغ عن الزهق ووقت الفراغ لديهم. r) توجد فروق إحصائية ذات دلالة معنوية بين عينة الدراسة (حيلهشوائي/حي فقير) لمقياس التوافق البيئي.

جدول رقم(•): اختبار (ت) T-Test لتوضيح الفروق بين عينة الدراسة لمقياس التوافق البيئي

\begin{tabular}{|c|c|c|c|c|c|}
\hline المعنوية & قيمة ن & المُعياري & المتوسط & العينة العة & المتغيرات \\
\hline \multirow{2}{*}{ غير دالة } & \multirow{2}{*}{$\cdot, 0 Y 7$} & 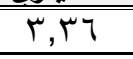 &, $7 \varepsilon$ & عشڤ| & \multirow{2}{*}{ البعد الأول: التوافق النفسي } \\
\hline & & $r, Y M$ & TV, $9 \leq$ & فيمر & \\
\hline \multirow{2}{*}{ غير دالة } & \multirow{2}{*}{$1, v \cdot 0$} & $0, \cdot \varepsilon$ & $\mu, 7 \Lambda$ & هى عشوائي & \multirow{2}{*}{ البعد الثاني: التوافق الأسري } \\
\hline & & $\varepsilon, \mu Y$ & $r \cdot, \cdot \Lambda$ & حي فقير & \\
\hline \multirow{2}{*}{ 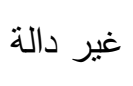 } & \multirow{2}{*}{ • } & $Y, O Y$ & $Y \Lambda, T \Sigma$ & حي عشوائي & \multirow{2}{*}{ البعد الثالث: التوافق اجتماعيا } \\
\hline & & $Y, Y Y$ & $r \wedge, V$ & 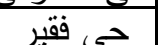 & \\
\hline \multirow{2}{*}{ 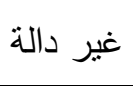 } & \multirow{2}{*}{$\cdot, 101$} & $Y, 01$ & $r \cdot, V \wedge$ & جي عشوائي & \multirow{2}{*}{ البعد الرابع: التوافقي مع البيئة } \\
\hline & & $1, r \wedge$ & $Y \cdot, \wedge \varepsilon$ & حي فقبر & \\
\hline \multirow{2}{*}{ غير دالة } & \multirow{2}{*}{$1, .04$} & $1, \vee \wedge$ & Tr,V & هى عشوائي & \multirow{2}{*}{ البعد الخامس: التوافق المهنى } \\
\hline & & $1, \wedge r$ & $Y \varepsilon, I T$ & & \\
\hline \multirow{2}{*}{ غير دالة } & \multirow{2}{*}{$\cdot, \leqslant 0 \wedge$} & $1 \cdot, .0$ & $I M Y, \Sigma \Lambda$ & عشوائي & \multirow{2}{*}{ الدرجة الكلية لدقياس التوافق } \\
\hline & & $V, I V$ & $1 \pi 1,7 \Lambda$ & فقير & \\
\hline
\end{tabular}

من الجدول السابق لتوضيح الفروق لعينة الدراسة لمقياس النوافق البيئى اتضح الاتى: لإنى

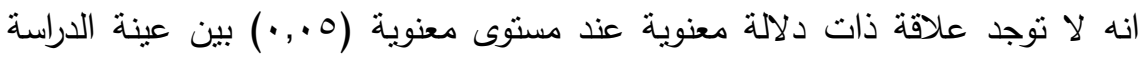

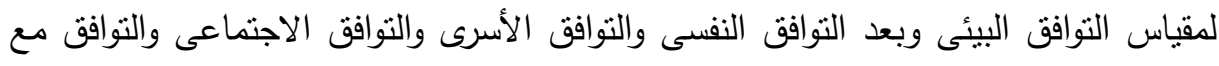
البيئة الفيزيقية والتوافق المهنى والدرجة الكلية لمقياس التوافق. 
جدول رقم(7): اختبار (ت) T-Test لتوضيح الفروق بين عينة الدراسة لمقياس التوافق البيئي تبعاً لمتغير النوع

\begin{tabular}{|c|c|c|c|c|c|c|}
\hline الالالةة & قيمة & الإنحعافياري & المتوسط & العدد & النوع & المتغيرات \\
\hline \multirow{2}{*}{$\cdot, 0$} & \multirow{2}{*}{$1,9 \leq \leq$} & $r, 79$ & rr,q & VA & ذكر & \multirow{2}{*}{ لبعد الأول: التوافق النفسي | } \\
\hline & & $\Gamma, 0 \wedge$ & Tr,AI & $V Y$ & آنتي & \\
\hline \multirow[b]{2}{*}{$\cdot, \cdots$} & \multirow{2}{*}{$q, 1 \leqslant r$} & $\varepsilon, \wedge q$ & $\Gamma, 7 \wedge$ & VA & ذكر & \multirow{2}{*}{ لبعد الثاتي: التوافق الأسري| } \\
\hline & & $v, 91$ & Y 1, q & $V Y$ & آنتي & \\
\hline \multirow{2}{*}{ } & \multirow{2}{*}{$r, \cdot v$} & $r, r q$ & 10,10 & $V \wedge$ & ذكر & \multirow{2}{*}{ البعد الثالث: التوافق } \\
\hline & & $1, \wedge 9$ & $\Gamma \varepsilon, 1$. & VY & آنثي & \\
\hline \multirow{2}{*}{ • } & \multirow{2}{*}{$1, \cdot{ }^{\prime}$} & $Y, V T$ & $r Y, T Y$ & $\mathrm{V \Lambda}$ & ذكر & \multirow{2}{*}{ 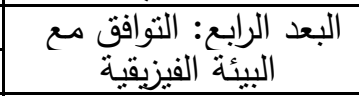 } \\
\hline & & $r, Y u$ & $r, 11$ & $V Y$ & آنتخ & \\
\hline \multirow[b]{2}{*}{ 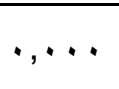 } & \multirow{2}{*}{$0, \vee \neg \leqslant$} & $I Y, V V$ & $r \cdot, 00$ & $\vee \wedge$ & ذكر & \multirow{2}{*}{ البعد الخامس: التوافق } \\
\hline & & $1 \pi, 10$ & $\Lambda, r_{0}$ & $V Y$ & آنتي & \\
\hline \multirow{2}{*}{$\cdot, \cdots$} & \multirow{2}{*}{1,009} & II,Y & 104,97 & $\mathrm{V \Lambda}$ & ذكر & \multirow{2}{*}{ الدرجة الكلية لمقياس } \\
\hline & & $19, \cdot r$ & $|r q, r|$ & $V Y$ & آنتخي & \\
\hline
\end{tabular}

من الجدول السابق لنتائج اختبار (ت) لتوضيح الفروق بين عينة الدراسة لابعاد مقياس

التوافق البيئي تبعاً لمتغير النوع ينتين الآتي: البعد الأول التوافق النفسي: وجود فروق ذات دلالة معنوية عند مسنوى معنوية (0., •) بين

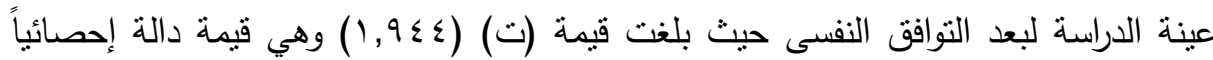
عند مستوى معنوية (0., •)، وبلغ متوسط عينة (الذكور) (T, (T) ومتوسط عينة (الإناث)

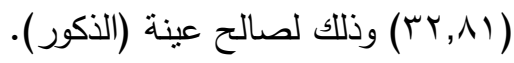
البعد الثاني التوافق الأسري: وجود فروق ذات دلالة معنوية عند مستوى معنوية (0., •) بين

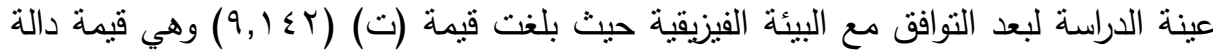

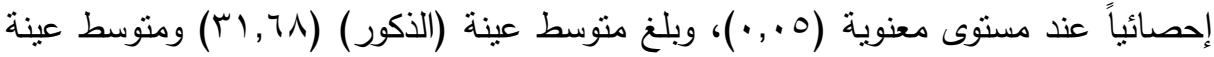

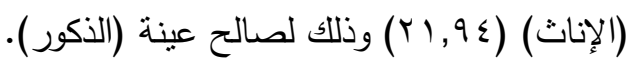


البعد الثالث التوافق اجتماعيا: وجود فروق ذات دلالة معنوية عند مستوى معنوية (0.,•)

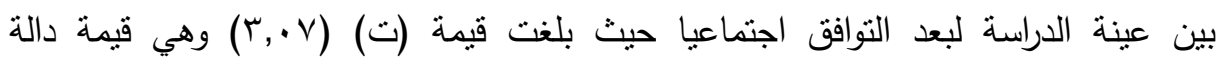

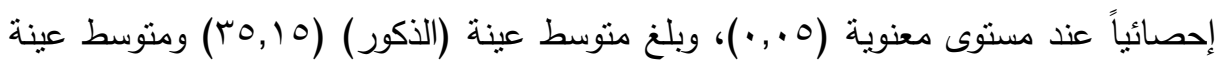
(الإناث) (1, (ب) وذللك لصالح عينة (الذكور ). البعد الخامس التوافق المهني: وجود فروق ذات دلالة معندة (الأكور).

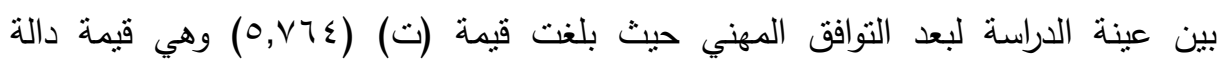

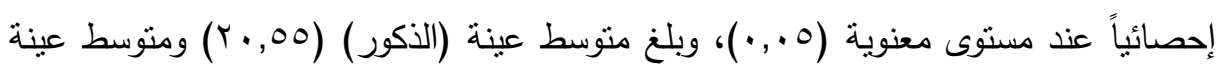
(الإناث) (^, (^) وذللك لصالح عينة (الذكور ). الارجة الكلية لمقياس التوافق: وجود فروق ذات دلالة معنوية عند مستوى معنوية (0., •)

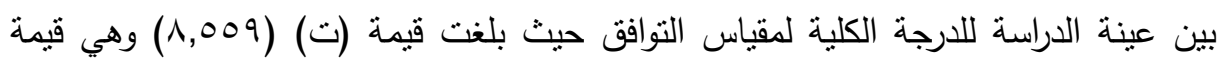

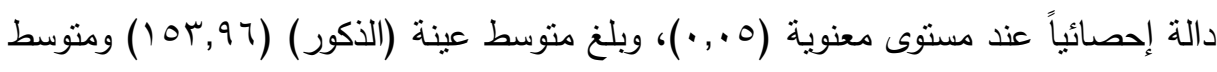

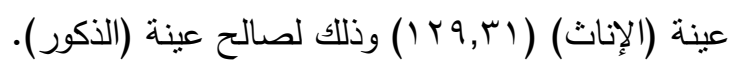

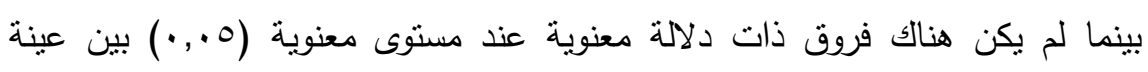
الدراسة تبعاً لمتغير النوع لبعد التوافق التوافق مع البيئة الفيزيقية. التفسير: البعد الاول: التوافق النفسى: اتضح من خلال الدراسة الميدانية انه يوجد فروق فى التوافق

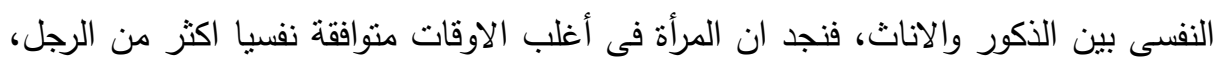

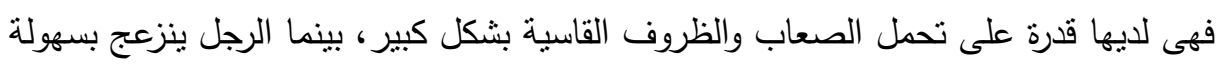
أكثر ، ويشعر بالفشل سريعا.

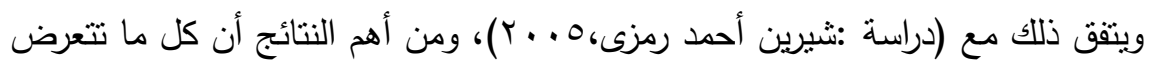

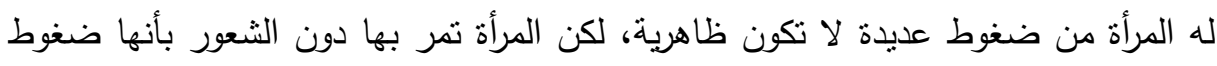
لانها اصبحت جزء من حياتها، كما وجدت علاقة بين الرضا والتوافق فى بعض الهن المجالات. 
ويتفق ذلك مع نظرية (التحليل النفسى لفرويد)، حيث يرى فرويد أن التوافق يتحقق عندما

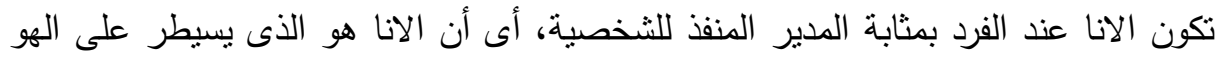

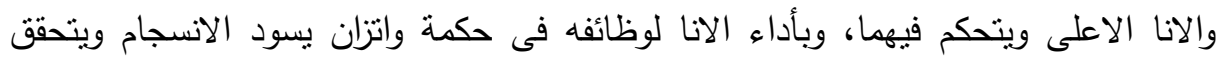

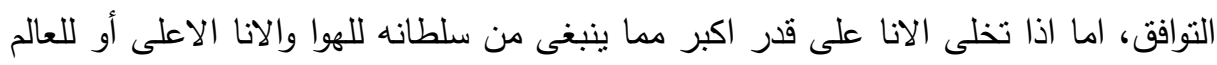

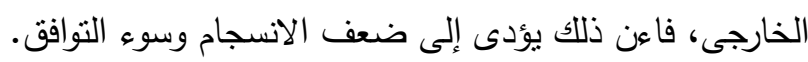
ويقول (كارل روجرز) من انصار المدرسة الانسانية:الى أن الافراد الذين يعانون من فن النهاء

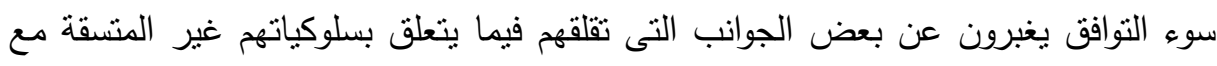

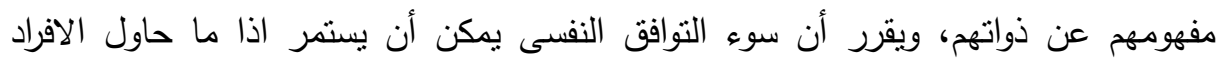

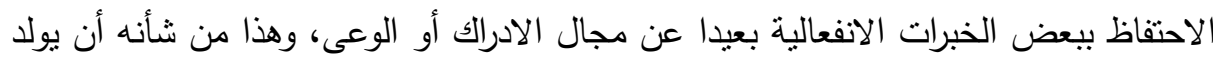
مزيدا من التوتر والاسى وسوء التوافق. البعد الثانى: التوافق الأسرى: تتسم الأسر في المناطق العشوائية بمجموعة من السمات التى

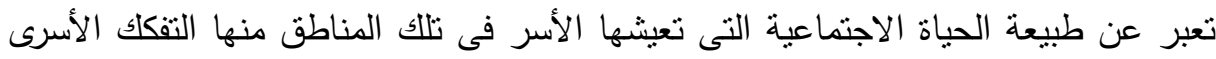

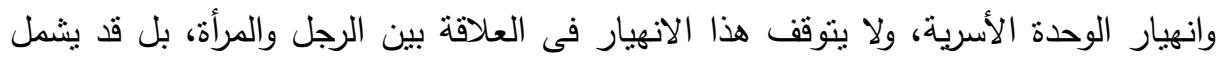

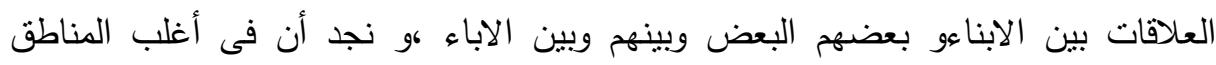

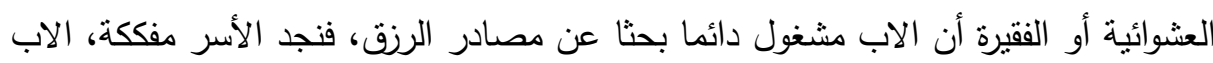

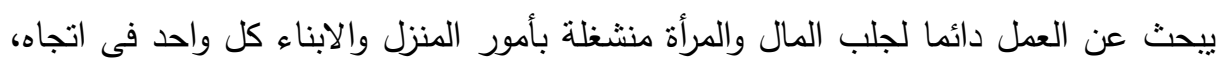
فلا نوجد قيم أو روابط تجمعهم مع بعض، حيث تشكل هذه القيم عصب الارتباط بينهم، وكما

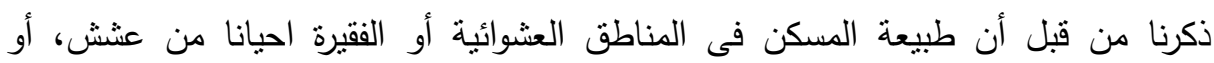

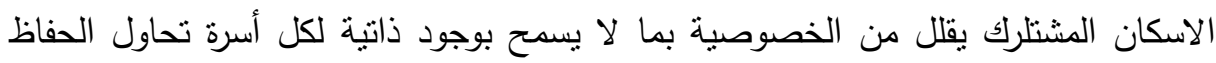

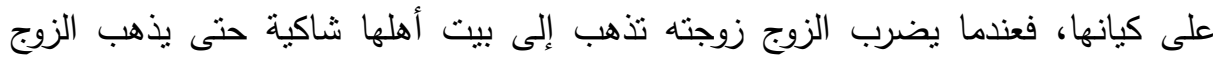

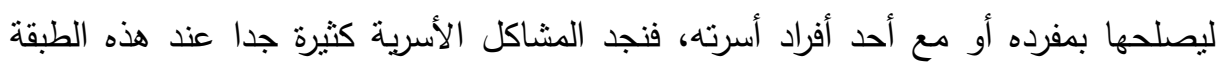
وأغلبها بسبب الظروف الاقتصادية الصعبة للاسر وعدم وجود دخل ثابت، وتقوم هذه الأسر

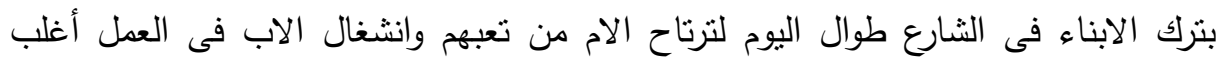

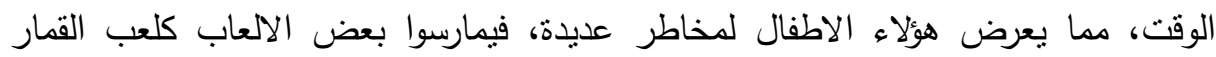

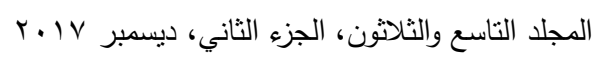


وتعاطى المخدرات، ويستخدمون المطاوى فى لعبهم مع بعض مما بياعد على انتشار ظاهرة اطفال الشوارع.

تلعب المرأة دور هام فى تلك المناطق الفقيرة، فنجد معاناة المرأة الدائمة، فعليها عبء كبير من ادارة أمور المنزل وتدبير الاكل والثرب وغيره وتربية الابناء، ونجد أن أساليب

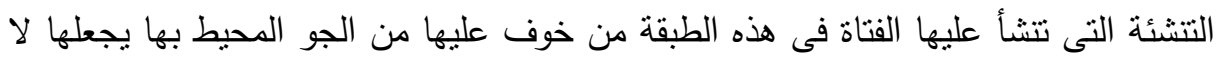

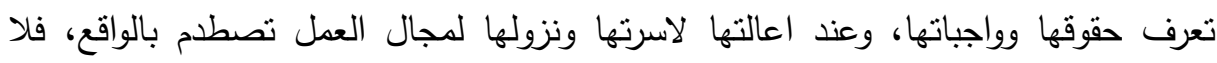

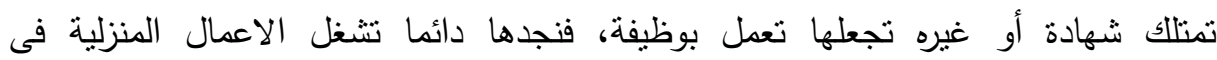
البيوت(شغالة) أو تبيع خضار على الرصيف أو بيع البقالة (فنقول أحدى الحالات: أنا نزلت

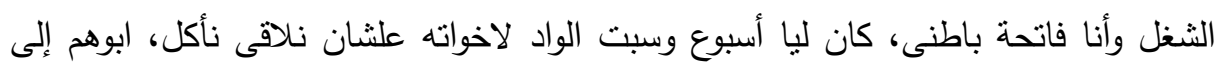

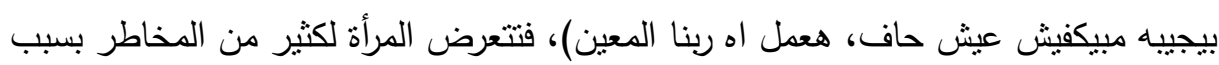

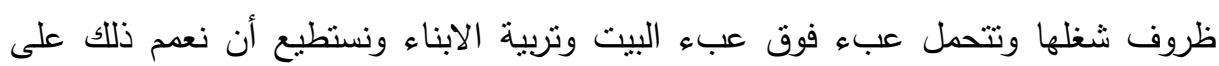
المرأة العاملة. البعد الثالث: التوافق الاجتماعى: اتضح من خلال الدراسة الميدانية أن كلا من الذكور والاناث لديهم نوافق اجتماعى، ويظهر ذلك بوضوح من خلال علاقات الجيرة، فالبنسبة للاناث

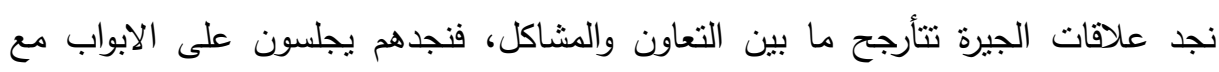

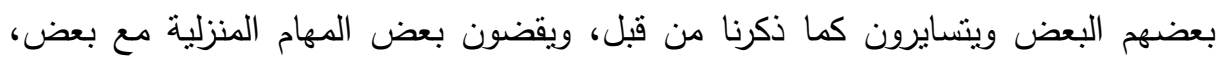

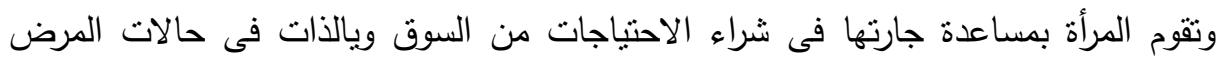

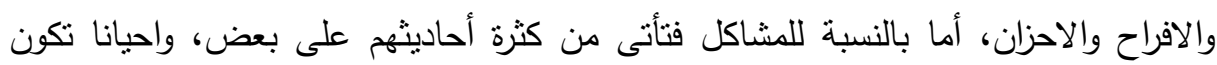

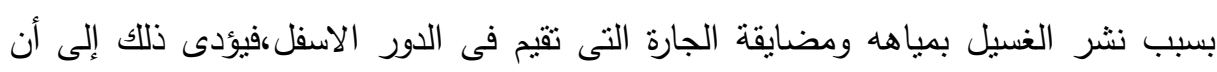

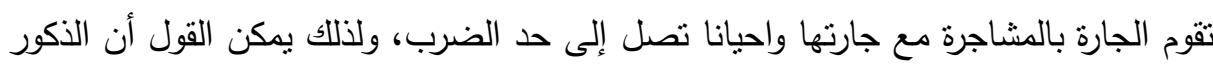
لايهم توافق اجتماعى أكثر من الاناث. 
ويذكر (أوسكار لويس ) فى نظريته عن ( ثقافة الفقر) والتى نتشكل تجسيم فى أنثكال

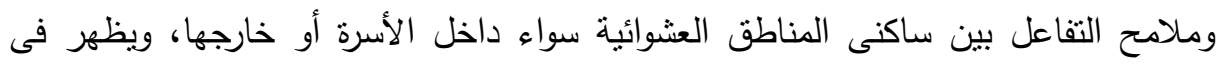
ملامح السلوك والتفاعل اللفظى لساكنى تلك المناطق والتى تصبغ طابع حياتهم الاجتماعية بصورة خاصة تجعلهم يختلفون عن عموميات ثقافة المجتمع القائمة.

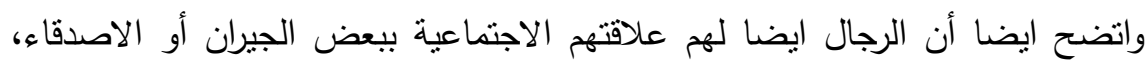

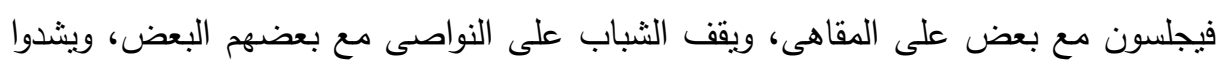

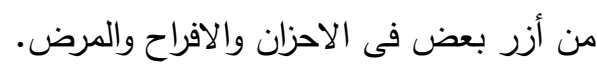
ويتفق ذلك مع (النظرية الاجتماعية) حيث برى انصار هذه النظرية أن هناك علاقة بين

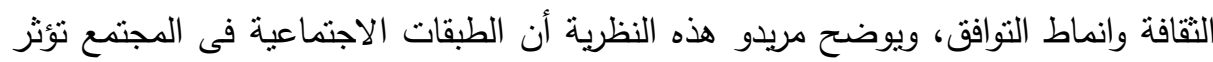

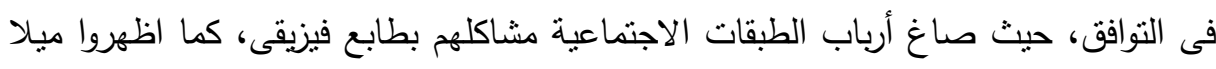
بسيط لعلاج المعوقات النفسية، هذا فى حين قام ذوى الطبقات الاجتماعية العليا بصياغة مشكلاتهم بطابع نفسى. البعد الرابع: التوافق المهنى: اتضح من خلال الدراسة الميدانية أن هناك فروق ذات دلالة احصائية بين الذكور والاناث فى التوافق المهنى، حيث يحاول الذكر بشتى الطرق أن ينوافق أنق

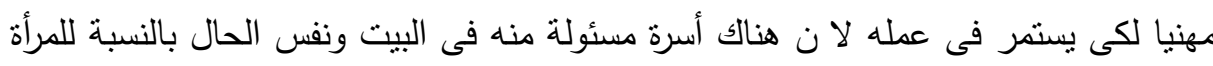
المعيلة، فيتحملوا متاعب العمل والزملاء فى العمل والرؤساء لكى بيستمروا.

\section{اللوكيايت}

1-اتخاذ قرارات سليمة وايجابية بشأن ظروف الفقراء واحتياجاتهم من قبل المجتمع والدولة.

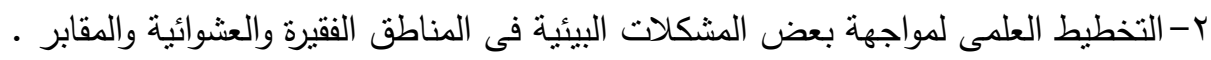

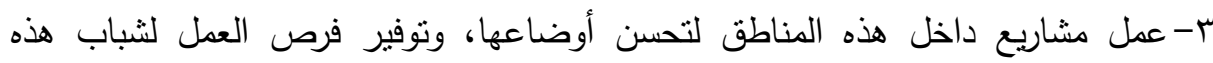

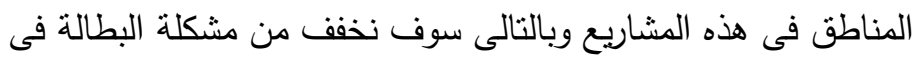

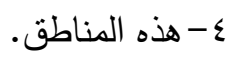


0- عمل مشاريع لتحسين الطرق فى المناطق العشوائية ورصفها وتمهيدها، لتحسين ظروف من يعيشون فيها. 1- الاهتمام بساكنى المقابر ومحاولة اعادة التخطبط لمساكنهم وفصلها عن الاحواش.

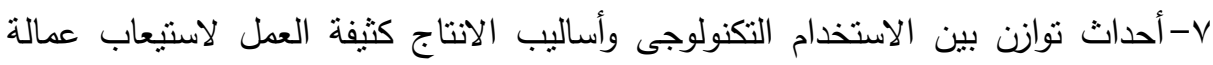
جديدة.

^-نشر كافة الخدمات الاجتماعية الاساسية وخدمات الاسرة مع أعطاء أولوية للمناطق الفقيرة

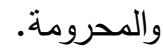
9-تعزيز برامج التوعية متعددة الاتجاهات لاحداث تغيير سلوكى فى جوانب تحديد النسل والوعى بمنطلبات وحجم الاسرة الرغوبة.

\section{zall}

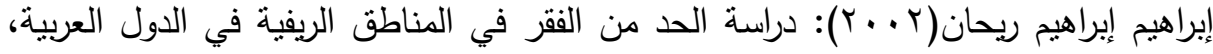

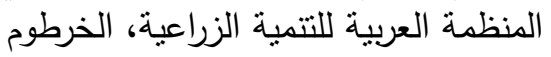

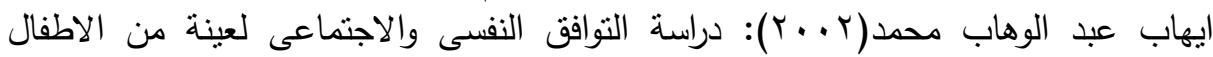

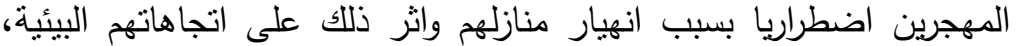

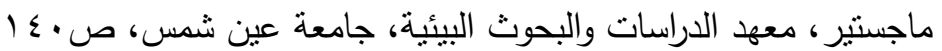

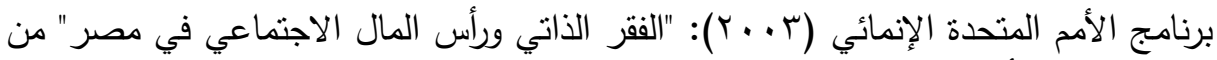

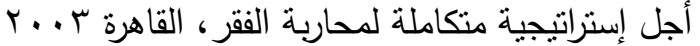

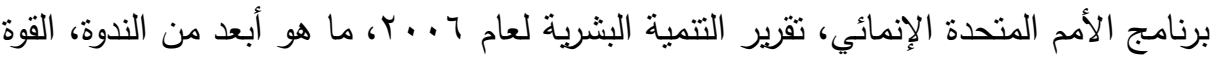

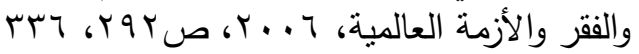

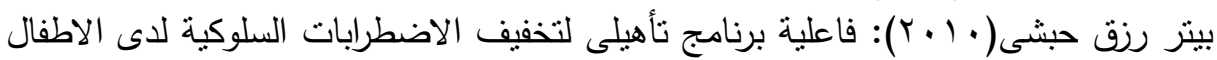
الذاتويون وتتمية اليات التوافق البيئى لديهم، معهد الدراسات والبحوث البياتئية،

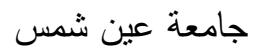

دافيد ماكينسون(يونيو 997 (1): كلمة التحرير، ترجمة جالال عباس، المجلة الدولية للعلوم

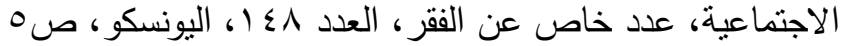

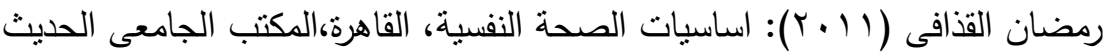

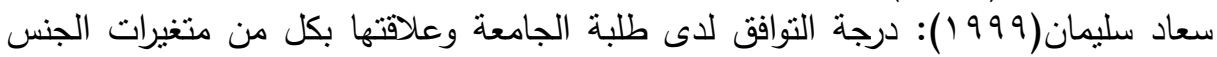

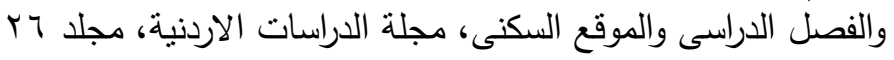

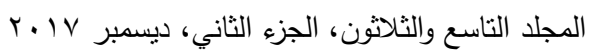




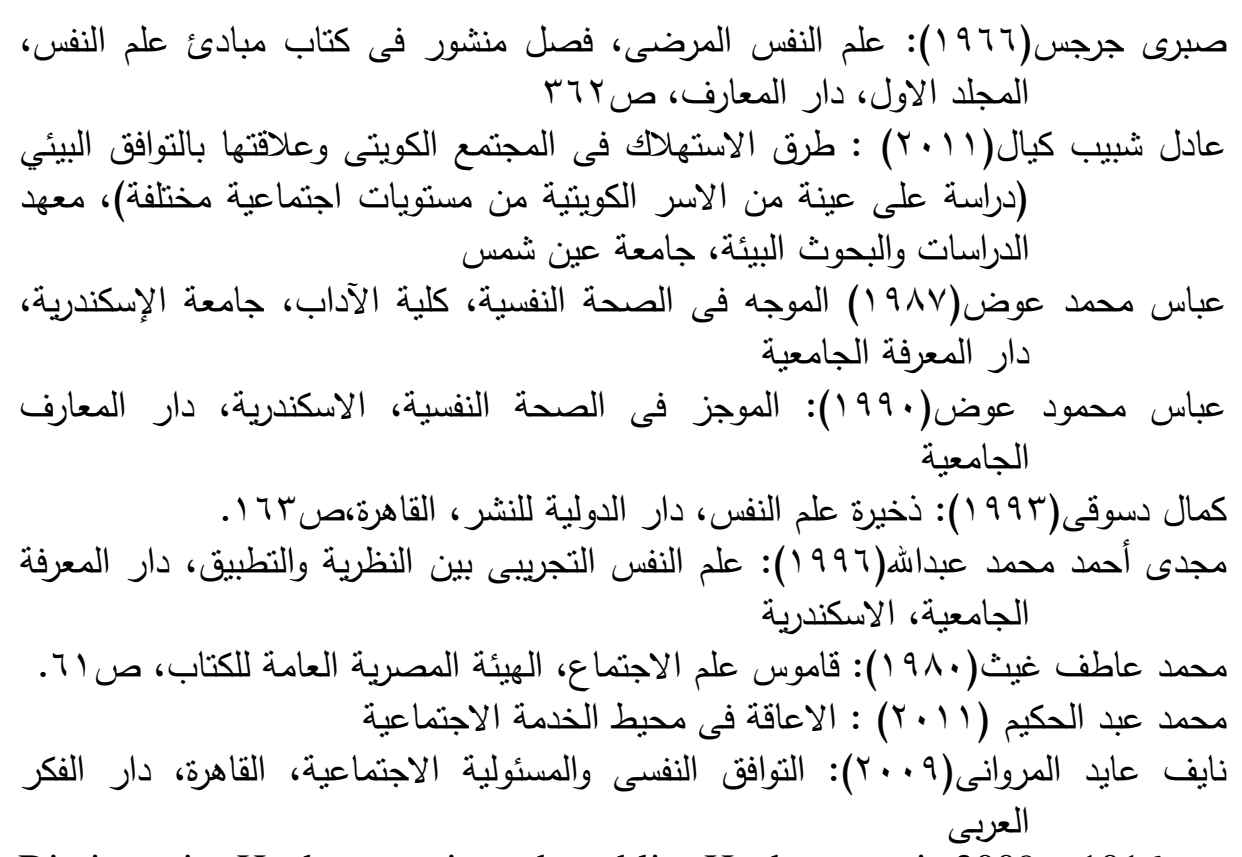

Dictionnaire Hachette maison de publier Hachette paris 2009 p 1016 http: www. menareport. Com /an / busineos/ 2.4

Landau ruth the adjustment of gouget widows who state university of new jersey new jersy new burn swick

LazarusR.S adjustment and personalitynew York,Mcgrow,hill,1961, $\mathrm{p}: 34$

Lenkowsky. Lirda . kiein: The Behavioral and psychoiogical adjustment family and Adoption.

Un Millenium project, Goals, Targets \& indicators, www. unmillenuim projiect. Org/gpa;s/ gti: htm. 


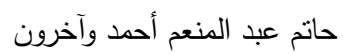

\title{
MECHANISMS OF ENVIRONMENTAL COMPLIANCE OF DIFFERENT CATEGORIES OF THE POOR PEOPLE IN CAIRO - AN ECOLOGICAL ANALYSIS
}

\author{
Ahmed, H. A. ${ }^{(1)}$; Al-Atiq, A. M. ${ }^{(1)}$ and Bishay, Dina, G. Z. ${ }^{(1)}$ \\ 1) Institute of Environmental Studies \& Research, Ain Shams \\ University
}

\begin{abstract}
This study drives at identifying the mechanisms of environmental convenience for divergent classes of Cairo city. The sample is applied on (150) male/female individuals using the Scale of Environmental Convenience as a means for collecting data to be applied on a sample of the poor (Monshaat Naser quarter - Roud El-Farag quarter - AlMegawreen cemetery). The researcher uses the social survey method for deducing social reality and analyzes the problem ecologically and for giving a conception of quality of life. The researcher uses multiple theories such as (Psychological analysis of Freud - The behavioral school - The human school - the ecological system theory). The research comes to several results which most important are: there are significant statistical differences between the study sample (tomb' residents/slum quarter) on Scale of Environmental Convenience. The study recommends giving more consideration and concern to that marginalized category in order to improve their conditions and overcome the diseases they are exposed to because of lack of cleanness, establishing as well some projects to overcome the unemployment problem and improve the condition.
\end{abstract}

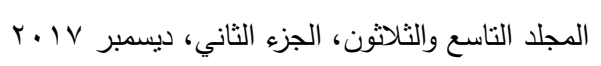

